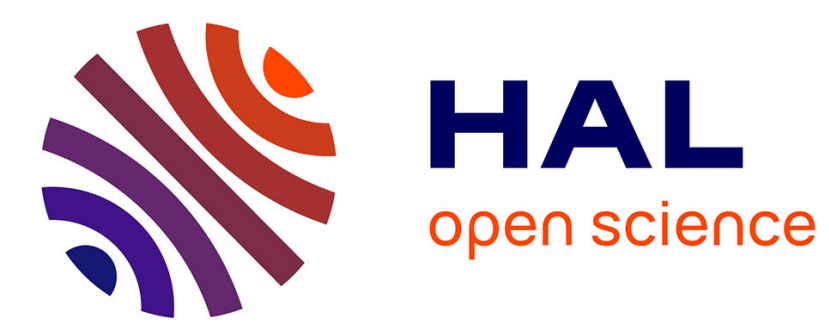

\title{
Regulating the financial analysis industry: Is the European Directive effective?
}

\author{
M. Dubois, Pascal Dumontier
}

\section{To cite this version:}

M. Dubois, Pascal Dumontier. Regulating the financial analysis industry: Is the European Directive effective?. 2009, 59p. halshs-00533084

\section{HAL Id: halshs-00533084 \\ https://shs.hal.science/halshs-00533084}

Submitted on 5 Nov 2010

HAL is a multi-disciplinary open access archive for the deposit and dissemination of scientific research documents, whether they are published or not. The documents may come from teaching and research institutions in France or abroad, or from public or private research centers.
L'archive ouverte pluridisciplinaire HAL, est destinée au dépôt et à la diffusion de documents scientifiques de niveau recherche, publiés ou non, émanant des établissements d'enseignement et de recherche français ou étrangers, des laboratoires publics ou privés. 


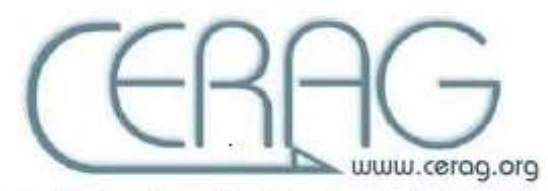

Centre d'Etudes et de Recherches Appliquées à la Gestion_U.M.R. C.N.R.S. 5820

\section{CAHIER DE RECHERCHE $n^{\circ}$ 2009-07 E2}

Regulating the financial analysis industry: Is the European

Directive effective?

DUBOIS Michel, DUMONTIER Pascal

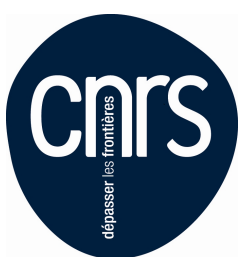

Unité Mixte de Recherche CNRS / Université Pierre Mendès France Grenoble 2

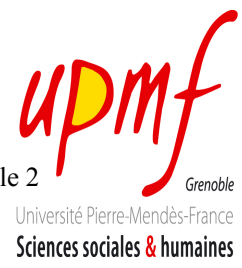

150 rue de la Chimie - BP $47-38040$ GRENOBLE cedex 9

Tél. : $0476635381 \quad$ Fax : 0476546068 


\section{REgulating THE FinANCIAL ANALYSIS INDUSTRY: IS THE EUROPEAN DIRECTIVE EFFECTIVE?}

\section{Current version: July 17, 2008}

Michel Dubois*

University of Neuchâtel

Pierre-à-Mazel 7

CH-2000 Neuchâtel

Michel.Dubois@unine.ch
Pascal Dumontier

University of Grenoble (IAE-CERAG)

BP 47

Fr - 38040 Grenoble cedex

Pascal.Dumontier@umpf-grenoble.fr

\footnotetext{
* This paper was written when the first author was visiting Simon Fraser University. Bertrand Bisson provided invaluable research assistance. We appreciate helpful comments from Laurent Frésard, Fred Sonney and seminar participants at Simon Fraser University. Financial support from the Swiss National Science Foundation (SNSF), grant No. 100012-105432, is gratefully acknowledged. The SNSF acts on a mandate from the Swiss Federal Government and promotes independent research.
} 


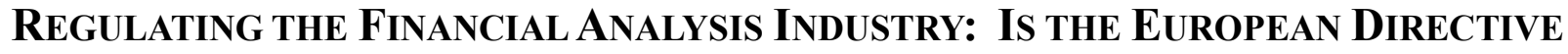 EFFECTIVE?}

In recent years, the US and the EC have witnessed the adoption of new regulations focused on financial analysts. This study investigates whether the European regulation, known as the Market Abuse Directive (MAD), changed the distribution of recommendations and increased their credibility. We find that the proportion of favorable recommendations significantly decreased and, to a lesser extent, that the proportion of unfavorable recommendations increased after the adoption of MAD. However, MAD did not completely eliminate overly optimistic recommendations emanating from financial institutions facing conflicts of interest. Concerning the market reaction to recommendations, we find that "Upgrades" and "Positive initiations" generated more positive abnormal returns post-MAD. Conversely, "Downgrades" generated more negative abnormal returns. We show that differences in investor protection across EC countries explain abnormal returns associated with analyst recommendations. We also find that financial institutions with reputation capital at stake were less prone to optimism and that conflicts of interest were not a significant determinant of the stock market reaction to recommendations either pre- or post-MAD. Finally, we examine whether the US regulation, adopted about two years before MAD, spilt over into the EC, making MAD redundant. Our results show that favorable recommendations on stocks listed on an EC stock exchange became dramatically less positive, and unfavorable ones became more negative following the adoption of the US regulations. However, investors reacted to this change only when MAD was adopted. Therefore, MAD has its own legitimacy, not because it changed analysts' behavior but because it heightened investor awareness of the change in analysts' behavior.

Key words: financial analysts, conflicts of interest, recommendations, Market Abuse Directive, European Union.

JEL classification: G12, G14, G24, G28, K22, M48 


\section{Introduction}

In recent years the US and the EC have witnessed the adoption of new regulations aimed at prohibiting selective disclosures of inside information and at curbing conflicts of interest affecting financial analysts. These regulations can be summarized as follows. First, corporate managers are not allowed to release information to any third party without disclosing it immediately to all market participants. Second, analysts' reports must include information useful in interpreting research outputs. Third, analysts have to disclose any business relationship with the firms they recommend.

The effectiveness of analyst research regulation deserves a thorough examination since, as noted by Mehran and Stulz (2007, p. 37), “...the majority of the papers do not suggest that analyst conflict of interest arising from investment banking activities had a systematic and persistent impact on the customers of analyst services". The empirical evidence from the US has failed to establish that investors are misled by biased research since market participants discount recommendations subject to conflicts of interest; see Lin and McNichols (1998), Michaely and Womack (1999), O'Brien, Mc Nichols and Lin (2005), Agrawal and Chen (2008) among others. This suggests that regulations devoted to analyst conflicts of interest might be unnecessary. Regarding Europe, two additional characteristics are likely to mitigate the impact of conflicts of interest. First, Clement, Rees and Swanson (2003) and Bolliger (2004) show that forecast accuracy is not a major factor in analysts' career progression. This is probably why Jegadeesh and Kim (2006) find that optimism in recommendations is lower in Europe than in the US. Second, European financial institutions providing investment research are mainly universal banks. Being more diversified in terms of revenue than their US counterparts, they are expected to put less pressure on sell-side analysts to 
win new business and to promote M\&A deals, IPOs or security offerings by issuing overoptimistic recommendations.

This study examines the effectiveness of the European provisions regulating analyst research (i.e. the Market Abuse Directive, generally referred to as MAD) by analyzing their impact both on the distribution of analysts' recommendations and on the abnormal stock returns associated with those recommendations. We find that the proportion of favorable recommendations ("Buy" and "Strong Buy"), which represents more than $48 \%$ of the recommendations under study, significantly decreased after the adoption of MAD. Conversely, but to a lesser extent, the proportion of unfavorable recommendations ("Sell" and "Strong Sell") increased. In addition, this change was more pronounced for recommendations issued on firms listed in countries where investor protection is high. Financial institutions providing investment banking services should be more prone to optimism because positive opinions are expected to attract investment banking business. Consistent with this idea, we show that, before the implementation of MAD, financial institutions exposed to conflicts of interest because of their investment banking activities released more favorable and fewer unfavorable recommendations than their peers facing no apparent conflicts. The adoption of MAD has reduced the proportion of favorable recommendations for both categories of institutions. Unsurprisingly, the decrease was more pronounced for those facing conflicts of interest. This is not the case for unfavorable recommendations. Financial institutions subject to conflicts of interest have issued fewer negative opinions than their peers with no apparent conflicts either pre- or post-MAD. The adoption of MAD has increased the proportion of unfavorable recommendations only for institutions with no apparent conflicts. Finally, if reputation is an important deterrent of conflicts of interest, financial institutions with strong reputation capital at stake should be less unduly optimistic than their peers; see 
Fang and Yasuda (2006), Ljunqvist, Marston and Wilhelm (2006). In addition, because MAD increases the visibility of recommendation distributions, the drop (increase) in favorable (unfavorable) recommendations should be more pronounced for highly reputed institutions. Our results confirm this intuition. Highly reputed institutions issued a lower proportion of favorable recommendations before the adoption of MAD than their less reputed competitors. Following the implementation of MAD, the proportion of favorable (unfavorable) recommendations issued by the former dropped (increased) more significantly compared to the latter.

In order to determine whether MAD has resulted in more credible recommendations, we examine the stock price response to recommendation releases. Since MAD was designed to restore trust in favorable recommendations, these should be associated with higher returns in the aftermath of the regulation. In contrast, because they became slightly more frequent, unfavorable recommendations might be associated with less significant negative returns. Controlling the quantity and the quality of information conveyed by recommendations, and considering differences in the level of cross-border investor protection, differences in conflicts of interest and differences in the reputation of financial institutions, our results show that abnormal returns generated by recommendations are significantly higher (lower) for "Upgrades" and "Positive initiations" ("Downgrades") since the adoption of MAD. Interestingly, we show that disclosure of potential conflicts resulting from analysts' ties with the companies they recommend did not change the stock market reaction to their recommendations. Conflicts of interest did not affect abnormal returns associated with "Upgrades" and "Positive initiations" either pre or post-MAD. During the same two periods, "Downgrades" issued by analysts facing conflicts of interest generated more negative abnormal returns than those issued by analysts with no apparent conflicts. We interpret these findings as evidence 
Dubois-Dumontier - Regulating the Financial Analysis Industry: Is the European Directive Effective?

that investors, who interpret optimistic recommendations conservatively, discounted optimistic recommendations appropriately before the adoption of MAD. In conjunction with investor protection, these results explain why European stocks react less to recommendations than US ones. We also find that reputation acts as a moderating factor of conflicts of interest induced by investment banking activities both before and after the adoption of MAD.

Numerous recommendations on European stocks are issued by financial institutions having to comply with the US regulations on analyst research (Reg FD, NASD Rule 2711 and NYSE Rule 472). Therefore, conflicts of interest in the EC may have been resolved, at least partially, by the US regulations that became effective more than two years prior to the adoption of MAD. Consequently, we check whether recommendations on European stocks issued by financial institutions operating in the US were affected by the adoption of the US regulations. Specifically, we compare the distribution of these recommendations and their associated abnormal stock returns before and after the adoption of US regulations. We find that the proportion of positive recommendations issued on European stocks decreased dramatically as soon as the US regulations were adopted. Conversely, the proportion of negative recommendations increased. However, abnormal returns did not change until MAD was adopted.

Our results complement the literature in several ways. First, this is the first study investigating the consequences of conflicts of interest on analyst research in an alternative institutional environment to the $\mathrm{US}^{1}$. Second, we provide evidence showing that the EC regulation on market abuse was useful, at least for some investors, because it aligned analysts' recommendations with their original intent. Third, we

\footnotetext{
${ }^{1}$ Mehran and Stulz have identified 397 papers on www.ssrn.com with "conflicts of interest" in the title or in the abstract prior to July 2006. On December $31^{\text {st }}, 2007$, this number came to 524 . These numbers show that research in this field is abundant. Surprisingly, it is exclusively based on US data.
} 
demonstrate that conflicts of interest are less acute in Europe than in the US and that reputation matters. Fourth, we show that national securities regulations are necessary despite the globalization of financial markets. The US regulatory system had a spillover effect on recommendations of EC stocks that became less optimistic after US regulations were passed. However, investors did not react to this shift until the European regulation became binding.

The remainder of our paper is organized as follows. Section 2 presents and analyzes the provisions of MAD. Section 3 reviews the related literature. Section 4 describes the sample selection. Section 5 provides empirical results on the impact of MAD on the distribution of recommendations. Section 6 examines how stock prices reacted to these changes. Section 7 presents evidence concerning the spill-over of US regulations into the EC and Section 8 presents our conclusions.

\section{Regulation of investment research in the EC}

In 1999, the European Commission launched the Financial Services Action Plan with the aim of promoting a fully integrated European financial market. To this end, several directives were adopted, among which Directive 2003/6/EC on 'Insider Dealing and Market Manipulation' in January 2003. This Directive, known colloquially as Market Abuse Directive, was complemented by two implementing Commission Directives, CD 2003/124/EC and CD 2003/125/EC in December 2003. European directives become legally binding only when they are incorporated into national laws. MAD gave Member States 
until October $12^{\text {th }}, 2004$ to transpose the provisions into local legislation ${ }^{2}$; see Ferrani (2004) and Hansen (2004).

The first objective of MAD is to preclude selective disclosures of information. Managers "must make complete and effective public disclosure of (all relevant) information, simultaneously in the case of an intentional disclosure and promptly in the case of a non-intentional disclosure" (Directive 2003/6/EC, article 6.3). Relevant information is price-sensitive information, i.e. "information which, if it were made public, would be likely to have a significant effect on the price" (CD2003/124, article 1). These provisions are very similar to those of the Regulation Fair Disclosure (Reg FD) adopted in 2000 by the SEC with the aim of eliminating trading profits resulting from unequal access to information. Under Rule 100 of Reg FD, managers are required to release material information simultaneously to all investors. The information has to be released promptly to all market participants if it was inadvertently disclosed.

The second objective of MAD is to harmonize standards for the "fair, clear and accurate presentation of information and disclosure of interests and conflicts of interest" ${ }^{\prime 3}$. In order to make analysts accountable for their recommendations, the identity of the persons, i.e. their name and job title, who prepared the recommendation and the name of the person legally responsible for the recommendation, must be disclosed. Recommendations made by teams of analysts with no individual names are therefore implicitly forbidden ${ }^{4}$. Facts must be clearly distinguished from opinions and interpretations. Estimates, which include forecasts and price targets, must be labeled as such. The methodology used to evaluate financial

${ }^{2}$ Germany did this on October $30^{\text {th }}, 2004$, but most Member States transposed MAD into national laws during the second semester of 2005 (i.e. Finland, France, Ireland, Italy, Netherlands, Great Britain and Spain) or even later (Belgium).

${ }^{3}$ Official Journal of the European Union, December 24, 2003, L339/73.

${ }^{4}$ Before the adoption of MAD, the proportion of recommendations issued by teams accounted for $20 \%$ of the recommendations issued by European analysts, see Bolliger (2004). 
instruments must be described. In addition to the time horizon and risk, the date at which the recommendation was released must be prominently indicated. Interestingly, any change in a recommendation that was issued during the last twelve months must be clearly indicated. Furthermore, financial institutions providing recommendations are required to disclose every quarter the proportion of "Buy", "Hold" and "Sell" recommendations issued for all stocks they follow.

The last objective of MAD is to limit the consequences of potential conflicts of interest that materialize at the level of the individuals who prepare the recommendation or have access to it before dissemination to market participants. Acknowledging the impossibility of completely eliminating these conflicts, the regulator adopted a pragmatic strategy. It consists of making investors aware of the conflicts by forcing the disclosure of any relevant information that might potentially affect the nature of the recommendation. Financial institutions are required to disclose the "effective organizational and administrative arrangements set up [...] for the prevention and avoidance of conflicts of interest" (CD2003/125, article 6.2). They must report on how the remuneration of the person preparing the recommendation is tied to investment banking transactions. Any person involved in the production of the recommendation must release her links with the recommended firm. Having acted as a lead manager or a co-lead manager in any securities offerings (stocks and bonds) or having advised the recommended firm in a M\&A over the twelve months preceding the recommendation must be disclosed as well. Finally, disclosure must be made if the financial institution recommending a firm holds a stake of $5 \%$ or more in the capital of the recommended firm or, conversely, if the recommended firm holds a stake of $5 \%$ or more in the capital of the financial institution. 
Dubois-Dumontier - Regulating the Financial Analysis Industry: Is the European Directive Effective?

The provisions of NASD Rule 2711 and NYSE Rule 472, adopted in the US in 2002, are very similar to those of MAD regulating conflicts of interest and the fair presentation of recommendations. They both impose disclosure of information helping to understand research outputs and to identify potential conflicts of interests. Several minor discrepancies are, however, noticeable. MAD does not make any reference to the individual protection of financial analysts from persons involved in investment banking activities working for the same financial institution. Nor does it refer to the educational level of financial analysts, or to the ban on reviewing the report before publication made on companies that are the subject of the research report. In contrast, NASD Rule 2711 and NYSE Rule 472 do not mention shareholding as a source of conflict. However, the main difference between the EC and the US regulations lies in the fact that there is no unified enforcement in the EC. MAD applies to all financial instruments admitted to trading on a regulated market of an EC Member State. Consequently, financial institutions issuing analyst reports have to comply with the rules of the Member State where recommended firms are listed ${ }^{5}$; see Enriques (2005). The competent country for supervising the enforcement of MAD is the one where the financial instrument is traded. Depending on the country, violations of the rules are considered as administrative, civil or criminal offenses and the penalties incurred vary widely from country to country; see Freshfields, Bruckhaus and Deringer (2006).

\section{New regulations and analysts' recommendations: Previous research}

Before turning to the evaluation of MAD, we briefly review previous research examining the consequences of Reg FD, NASD Rule 2711, or NYSE Rule 472 for the US stock markets.

\footnotetext{
${ }^{5}$ Official Journal of the European Union, April $12^{\text {th }}$, 2003, L96/18 al. 35.
} 


\subsection{Selective disclosure}

The introduction of Reg FD was highly disputed. Proponents of the regulation argue that, by creating information asymmetries, selective disclosure creates opportunities for trading profits at the expense of uninformed investors, thus reducing liquidity and increasing the cost of capital of listed firms. Opponents argue that private conversations and conference calls are essential to maximize the information flow. Prohibiting the use of this source of information reduces the quantity and the quality of available information and, therefore, market efficiency.

Previous research essentially studied whether Reg FD reduced the accuracy of analysts' earnings forecasts and modified their dispersion; see Heflin, Subramanyam and Zhang (2003), Sunder (2003), Brown, Hillegiest and Lo (2004), Eleswarapu, Thomson and Venkataraman (2004), Agrawal, Chadha and Chen (2006), Mohanram and Sunder (2006) and Ahmed and Schneible (2007). There is no empirical evidence of a dramatic effect of Reg FD on either the quantity or the quality of available information.

Concerning recommendations, Reg FD did not alter the impact of downgrades and upgrades on stock prices either; see Ferreira and Smith (2006). However, since the adoption of Reg FD, investors attribute less value to recommendations that previously could have benefited from private disclosure, i.e. those issued by financial institutions with investment banking ties with the recommended firms; see Cornett, Tehranian and Yalcin (2007).

\subsection{Conflicts of interest and analysts' forecasts and recommendations}

Two recent surveys examine the extensive empirical literature devoted to conflicts of interest in the financial analysis industry; see Dubois and Dumontier (2006) and Mehran and Stulz (2007). Both 
underline the unequivocal evidence showing that earnings forecasts are not affected by conflicts of interest, at least for stocks listed in the US. A straightforward reason for these results, empirically confirmed by Ljunqvist et al. (2006), is that favorable forecasts do not attract investment banking business. This is probably because analysts build their reputation on the accuracy of their earnings forecasts, which is easily assessable ex-post. In contrast, erroneous investment recommendations are much more difficult to detect. Hence, this is where analysts' propensity to issue biased research may come into play. Analyst optimism about the firms they recommend is a well established fact in the US stock market. There are at least three reasons for analysts to be optimistic. First, analysts may be positively biased because they follow firms that have good future prospects (endogenous selection) and they give up following firms which are not as promising. Second, positive recommendations generate more trades because short selling is not always possible. Thus, they have no incentive to issue negative advice. Third, conflicts of interest, and in particular, conflicts of interest related to investment banking, are a natural source of optimism.

In accordance with the optimism bias hypothesis, empirical studies find that affiliated analysts and, more generally, analysts working for investment banks issue recommendations with significant upward biases; see Michaely and Womack (1999) and O'Brien, McNichols and Lin (2005), James and Karceski (2006). These findings are highly disputed, however, and opposing views are held by many academics; see Cowen, Groysberg and Healy (2006), Jacob, Rock and Weber (2007), Lin and McNichols (1998), McNichols, O’Brien and Pamukcu (2006) and Bradley, Jordan and Ritter (2007).

Systematically following recommendations issued by investment banks hurts investor's portfolio performance because these banks are reluctant to downgrade stocks compared to independent research 
firms; see Barber, Lehavy and Truman (2007). More specifically, Mikhail, Walther and Willis (2007) show that small investors tend to trade more after upgraded and "Buy" recommendations than they do after downgraded and "Sell” recommendations. In particular, small investors take all recommendations for granted while sophisticated investors trade only on "Strong Buy" or "Strong Sell" recommendations; see Malmendier and Shanthikumar (2007). These findings suggest that small investors are the main victims of analyst conflicts of interest. Sophisticated investors are immune from the biases that contaminate recommendations.

Theoretically, Hayes (1998) proves that incentives to generate trading commissions affect both the accuracy and the availability of analysts' reports. In particular, incentives to provide research are stronger for stocks which are expected to perform well. For these stocks, reports are more accurate because analysts gather more information. As Irvine (2001) shows, brokerage activities also distort analysts' judgment because brokerage volume is higher for covered stocks and coverage helps brokers increase their market share. Jackson (2005) finds that favorable recommendations issued by brokerage firms increase stock trades in the short run. Both theoretical and empirical results show that brokerage activities alone can induce biased research.

The results presented above suggest that regulating analysts' activities could be, to a large extent, unnecessary for three major reasons. First, financial institutions with a strong stake in investment banking services must preserve their credibility. This prevents them from issuing misleading forecasts or recommendations. Second, competition moderates the propensity to issue overly optimistic recommendations; see Hong and Kacperczyk (2007) and Sette (2007). The introduction of additional constraints could deter competition and, as a result, reduce or even annihilate the beneficial effects of 
regulatory reforms. Third, sophisticated investors mainly focus on earnings forecasts that do not suffer from conflicts of interest and they are aware of the biases affecting recommendations. Consequently, the benefits of regulating financial analysts could be limited to better protecting small investors from opportunistic behavior of analysts working for non-reputable investment banks or for brokerage institutions involved in securities trading that cover firms which are followed by few analysts. In such a setting, a regulation applicable to the financial analysis industry as a whole could generate costs far exceeding the expected benefits.

\section{Data and sample}

Our initial sample consists of all recommendations issued on EC firms listed in the following countries: Austria, Belgium, Denmark, Finland, France, Germany, Great Britain, Ireland, Italy, the Netherlands, Portugal, Spain and Sweden. The period under study starts January $1^{\text {st }}, 1998$ and ends on May $30^{\text {th }}, 2007$. Due to lagged variables, the information was collected from 1997 onward.

We use three sources of data. First, daily stock prices and national stock market indices were collected from Datastream from January $1^{\text {st }}, 1997$ to May $30^{\text {th }}, 2007^{6}$. Second, analyst recommendations and forecasts were collected from the I/B/E/S International Historical Detail File database. As discussed previously, MAD applies to brokers with their headquarters or a branch in the EC. Hence, we retained recommendations issued by brokers who were under the jurisdiction of a country member of the EC. Consistent with previous research, we also excluded recommendations for which the following 
information was missing: firm, broker or currency codes. Financial institutions issuing fewer than five recommendations over the sample period were also eliminated.

From the Security Data Company's (SDC) database, we collected firms involved in IPOs, SEOs, debt issuance and M\&As. We also collected bookrunner and manager names, the amount and the date at which transactions took place from January $1^{\text {st }}, 1997$ to December $31^{\text {st }}, 2006$. Merging I/B/E/S and Datastream data can be done easily using tickers and dates, whereas merging $\mathrm{I} / \mathrm{B} / \mathrm{E} / \mathrm{S}$ and SDC data is far more challenging. To do so, we used the broker name associated with the broker masked code and manually matched the names of the bookrunner(s), manager(s) and advisor(s) in the SDC. Nelson Directories helped us determine which recommendations were issued by independent research firms with no brokerage business and no investment banking business. We found no recommendations made by such firms in our sample.

Table 1, Panel A, reports summary statistics of recommendations released from January $1^{\text {st }}, 1998$ to May $30^{\text {th }}, 2007$ sorted by country. Column 1 and column 2 indicate the number of firms and the number of brokers appearing in the sample. Overall, the sample contains 5106 firms. The average number of firms per year is 2613 . The total number of brokers is 273 and the average number per year is 154 . Column 3 shows the number of recommendations sorted by country and year, and columns 4 to 8 show the number of recommendations split by level (Strong Buy, Buy, Neutral, Sell, and Strong Sell).

$$
\text { Insert }<\text { Table } 1>\text { about here }
$$

\footnotetext{
${ }^{6}$ Datastream translated prices of the Euro zone stocks in EUR before $01 / 01 / 1999$. The exchange rate depends on the country but is constant for every stock so that it has no impact on most stock returns. $\mathrm{I} / \mathrm{B} / \mathrm{E} / \mathrm{S}$ did not follow the same rule, which means an adjustment had to be made from 1996 to 1999 for earnings.
} 
In accordance to their stock market size, three countries, namely Great Britain, Germany and France account for $68 \%$ of the firms and $61 \%$ of the recommendations. The studied recommendations are issued on firms listed in countries where securities laws stem from an English legal origin (31\%), a French legal origin (40\%), a German legal origin (16\%) or a Scandinavian legal origin (13\%).

Panel B shows the statistics by year. Contrary to conventional belief that more regulation should discourage brokers from making recommendations, there is no clear break in the number of recommendations over time. The proportion of "Strong Buy" (17.55\%) and "Buy" $(29.42 \%)$ is much lower than in the US over a comparable period. Conversely, the proportion of "Strong Sell" (5.15\%) and "Sell" (13.08) is higher, confirming that the structure of recommendations is different in Europe from that observed in the US; see Jegadeesh and Kim (2006, p. 282).

\section{Did MAD change the distribution of recommendations?}

To gauge the effectiveness of MAD in providing investors with more reliable recommendations and in curbing conflicts of interest, we examine the impact of MAD on the distribution of recommendations. In this section, we present the hypotheses, the research design, and the results related to the shift in the distribution of recommendations. 


\subsection{Hypotheses}

MAD provisions that aim at improving the fair presentation of recommendations should lead to a decline in the number of uninformative optimistic recommendations ${ }^{7}$. Hence, the first research question is whether the adoption of MAD changed the distribution of recommendations or not. Thus, we state our first hypothesis as follows.

Ha1: The proportion of favorable (unfavorable) recommendations decreased (increased) after the adoption of MAD.

Because of MAD provisions on conflicts of interest, brokers facing such conflicts should experience a drift towards a smaller proportion of favorable recommendations. In order to examine whether the disclosure of potential conflicts modified the distribution of recommendations, we set our third hypothesis as follows.

Ha2: The decrease (increase) in the proportion of favorable (unfavorable) recommendations following the adoption of MAD is higher for financial institutions having conflicts of interest.

Finally, as Fang and Yasuda (2006) argue, analyst reputation is a strong deterrent of conflicts of interest because financial analysts are inclined to preserve their human capital. Similarly, Ljunqvist et al. (2006) show that investment banks with strong reputation at stake are less prone to issue optimistic recommendations. On this subject, Mehran and Stulz (2007) conclude that greater reputation capital helps control conflicts of interest. Assuming that reputation has a moderating effect on conflicts of interest is equivalent to saying that financial institutions with a high reputation capital at stake are more reluctant to destroy it by issuing biased recommendations. Moreover, the disclosure of conflicts of interest should 
restrain these financial institutions more strongly from issuing optimistic research because the reputational cost of issuing misleading recommendations is higher for them. This leads to our fourth hypothesis.

Ha3: The proportion of favorable (unfavorable) recommendations was lower (higher) pre-MAD for financial institutions with a high reputation capital at stake, and the decrease (increase) in this proportion was higher post-MAD.

\subsection{Research design and variables}

In order to analyze the impact of MAD on the distribution of recommendations, we test whether the proportions of favorable (unfavorable) recommendations changed post-MAD. The variables of interest are defined as follows.

\subsubsection{Recommendations}

Recommendations are coded using a number between 1 and 5 ("Strong Buy" = 5 to "Strong Sell" = 1). As in previous studies, we reversed the scale used by $\mathrm{I} / \mathrm{B} / \mathrm{E} / \mathrm{S} /$ in order to have positive (negative) values for upgrades (downgrades). Then, we assign recommendations in three groups: favorable ("Strong Buy" and "Strong Sell"), neutral and unfavorable ("Strong Sell" and "Sell"). While I/B/E/S splits recommendations into five categories, some financial institutions use a three or four category rating scale. In addition, limiting the number of categories makes interpretation easier.

\subsubsection{Adoption of the Directive}

As Mulherin (2007, p. 424) mentions " a thornier issue in implementing regulatory event studies is that regulatory change occurs via a lengthy and uncertain process making it difficult to pinpoint when the

\footnotetext{
${ }^{7}$ It is unclear whether anti-selective disclosure should impact, or not, the distribution of recommendations. We examine this
} 
market responds to the new regulation". MAD is no exception with respect to this issue. The whole process was initiated by the adoption of codes of ethics at the national and international levels and then by the adoption of equivalent regulations in the US. This was followed by Commission Directives and, eventually, by the transposition of these directives into national laws. However, our goal being to test whether the regulation had a permanent effect, the exact date is not critical. Since penalties incurred for violations of the law are country specific, we retain the specific date at which the corresponding law was enacted in each country as the relevant date. This choice is conservative (i.e., it makes it more difficult to detect the effect of the law) because financial institutions could have decided, on their own, to comply with MAD before its adoption by the corresponding Member State. To measure the change in the regulation induced by $\mathrm{MAD}$, we define a dummy variable, PostLaw $w_{j, t}$, equal to one (zero) if the recommendation was issued after (before) the adoption of the law in the country where the recommended firm $j$ is listed.

\subsubsection{Public Enforcement}

The measure of public enforcement is adapted from La Porta et al. (2006). We use the variable "Public Enforcement" $\left(\right.$ PubEnf $\left.f_{j, t}\right)$ as a proxy for the effectiveness of the national regulation under which the recommended firm $j$ is listed. This variable is designed to proxy for the role of the agencies in charge of supervising the national stock exchanges (Supervisor) and the sanctions incurred when the law is violated. In this study, we use the three sub-indexes defined by La Porta et al. $(2006$, p. 11) concerning the role of the Supervisor. Two additional sub-indexes are defined to proxy for the administrative and the criminal

issue in Section 6.5. 
sanctions in case of violation of the law. $\left(\right.$ PubEnf $\left._{j, t}\right)$ is the arithmetic mean of these five sub-indexes. It aims at measuring the distance prevailing between national regulations; see Appendix 1.

\subsubsection{Conflicts of interest}

Our first measure of conflicts of interest is dictated by the provisions of MAD. Accordingly, underwriters or advisors in M\&As issuing recommendations on firms they had business with over the past twelve months are classified as having a conflict of interest when they recommend these stocks (CD2003/125, Art. 6, al. 1d). Consequently, we use a dummy variable $C M A D_{b, j, t}$ which is equal to one for recommendations under "C"onflict (as defined by "MAD") and zero otherwise. Hereafter, we label "Underwriters" the financial institutions that have advised M\&As or underwritten securities of a firm they recommend over the twelve months preceding the recommendation issue. We find 4601 recommendations potentially affected by conflicts of interest as defined by MAD $(C M A D=1)$. This number is surprisingly small since it represents $1.84 \%$ of the recommendations issued over our sample period. It shows that the law was extremely conservative in defining conflicts arising from investment banking activities.

Monetary incentives go beyond current business. As explained in Section 3.2, increasing market share in the investment banking market could also motivate optimistic recommendations. Hence, all investment banks can be suspected of issuing overly optimistic recommendations, even though they have no current business relationship with the firm they recommend. Therefore, we also use a less restrictive measure of conflict of interest inspired from Cowen et al. (2006). A broker is classified as having a conflict of interest if he has had investment banking business ${ }^{8}$ over the past twelve months; hereafter, we will refer to these brokers as "Investment Banks". The remaining firms are refered to as "Pure Brokers" since there are no 
independent analyst firms in our sample. Following this definition, we construct a dummy variable $C I B_{b, t}$ equal to one for Investment Banks and zero otherwise. Note that our measure is not forward looking since the classification of a broker is known at the time the recommendation is issued.

\subsubsection{Reputation}

Our proxy for reputation is similar to Ljunqvist et al. (2006). Every year, we rank underwriters based on the proceeds of IPO/SEOs and bond issues and we rank advisors in M\&As based on the value of the merger or acquisition. To be classified as having a high reputation, investment banks has to appear in the first decile of at least one of these three groups. We define the variable $\operatorname{Rep}_{b, t}$ (for reputation) as a dummy variable equal to one if the recommendation emanates from an investment bank with a high reputation and zero otherwise. The sample contains 54325 recommendations issued by high reputation investment banks.

\subsection{Shift in the distribution of recommendations levels}

Table 2 reports the results for our hypotheses related to the distribution drift of recommendations.

$$
\text { Insert }<\text { Table } 2>\text { about here }
$$

Our first hypothesis states that the proportion of favorable (unfavorable) recommendations decreased (increased) after MAD was passed. Table 2, Panel A, reports unconditional proportions pre-MAD and post-MAD. The proportion of "Strong Buy" and "Buy" recommendations decreased by 1.19\% from $47.22 \%$ to $46.03 \%$ (z-stat $=-4.89$, significantly different from 0 at the 1 percent level) after MAD was passed. Similarly, the proportion of "Sell" and "Strong Sell" recommendations increased by a mere $0.51 \%$

\footnotetext{
${ }^{8}$ Banks acting only as managers or co-managers are extremely rare in Europe.
} 
from $18.12 \%$ to $18.65 \%$ (z-stat $=2.71$, significantly different from 0 at the 1 percent level). Thus, we do not reject $\mathrm{Ha} 1^{9}$.

Our second hypothesis relates the distribution of recommendations to public enforcement. In order to test this hypothesis, we built three country groups using PubEnf ${ }_{j, t}{ }^{10}$. Results in Table 2, Panel B shows that the proportion of favorable recommendations dropped by $3.27 \%$ (z-stat $=-6.02$, significantly different from 0 at the 1 percent level) in countries with a high level of enforcement. In the remaining countries, this change was insignificant. Note also that proportions of favorable recommendations across groups converged post-MAD $($ High $=46.63 \%$, Medium $=46.43 \%$, Low $=44.38 \%)$. The proportion of unfavorable recommendations did not change significantly in countries with high protection. Consistent with the idea that recommendations were less optimistic in countries with low investor protection because of reputation, the proportion of unfavorable recommendations decreased (significant at the 5.2 percent level) post-MAD. However, this proportion increased from $20.33 \%$ to $22.03 \%$ (z-stat $=2.35$ significantly different from 0 at the 5 percent level) in countries with a medium level of enforcement, a fact that is difficult to reconcile with existing theories.

Our third hypothesis states that the decrease (increase) in the proportion of favorable (unfavorable) recommendations following the adoption of MAD is higher for financial institutions facing conflicts of interest. Results reported in Table 2, Panel C are consistent with this hypothesis. The decrease was

\footnotetext{
${ }^{9}$ The decrease in favourable recommendations (60\% vs $\left.43.30 \%\right)$ and the increase in unfavourable recommendations (4.50\% vs $12.10 \%$ ) were more pronounced in the US. This data are extrapolated from Ertimur et al. (2007, p. 592, Table 3). Their sample period contains recommendations for the years 1993-2004 excluding those issued between October $23^{\text {rd }}, 2003$ and May $9^{\text {th }}, 2002$.

${ }^{10}$ Countries with a high level of enforcement include France and Great Britain. Countries with a medium level of enforcement include Denmark, Finland, Ireland, Italy, Portugal and Spain, while countries with a low level of enforcement include Austria, Belgium and Germany.
} 
dramatic (-6.76\% from $62.07 \%$ to $55.31 \%)$ for financial institutions potentially affected by conflicts of interest as defined by MAD $(C M A D=1)$. Interestingly, the proportion of favorable recommendations issued by financial institutions not affected by conflicts of interest $(C M A D=0)$ also decreased significantly post-MAD, but to a lesser extent $(-1.13 \%)$. The broader definition of conflicts of interest provides another interesting perspective. While the proportion of unfavorable recommendations issued by brokers affected by conflicts $(C I B=1)$ decreased significantly by $1.78 \%$ from $48.57 \%$ to $46.79 \%$, the proportion of favorable recommendations of those unaffected did not significantly change. Concerning unfavorable recommendations, the adoption of MAD did not change the proportion of unfavorable recommendations significantly, at the 1 percent level (the change is positive and significant at the 5 percent level for $C I B=0$ ), either for recommendations potentially affected by conflicts or not. When we examine Table 2, Panel C, in cross-section, we observe a higher (lower) proportion of positive (negative) recommendations for both underwriters and investment banks pre-MAD, which signals potential conflicts of interest. This proportion decreased (increased) significantly post-MAD. Based on all these results, we do not reject Ha3 for favorable recommendations.

Consistent with Ha4, results in Table 2, Panel D show that the proportion of favorable (unfavorable) recommendations decreased (increased) significantly at the 1 percent level by $6.33 \%(2.54 \%)$ for financial institutions with high a reputation. This proportion did not change significantly for institutions with low reputation. The role of reputation was clearly exacerbated post-MAD. However, there are fewer negative recommendations for these financial institutions both pre-MAD and post-MAD.

To summarize, the proportion of positive recommendations has decreased since the adoption of MAD. The drop was more pronounced for financial institutions exposed to conflicts of interest and for those with 
a high reputation capital at stake. Since the adoption of MAD, institutions with a high reputation capital at stake became highly selective. Only 38 percent of firms they recommended obtained a favorable rating as opposed to 48 percent overall favorable ratings coming from the institutions with no reputation at stake. Following the adoption of MAD, the proportion of negative recommendations has increased significantly but only slightly. This result is essentially driven by institutions with high reputation at stake. Disclosure of sources of potential conflicts of interest did not affect the proportion of unfavorable opinion. Overall, our results suggest that MAD reduced the gap between the proportion of favorable and unfavorable recommendations, but it did not completely eliminate it ${ }^{11}$. Yet to be examined is how the changes in the distribution of recommendations translated in terms of stock price reaction.

\section{Did MAD change the stock price reaction to recommendations?}

In this section, we develop hypotheses that closely parallel those related to the shift in the distribution of recommendations. We present the research design, descriptive statistics concerning revision of recommendations and the results related to the stock price impact of recommendations under both regulatory regimes.

\subsection{Hypotheses}

The elimination or the decrease in the number of unduly optimistic recommendations resulting from the adoption of MAD should restore trust, which in turn should translate into higher stock price revisions. In contrast, more frequent "Negative initiations" and "Downward" revisions should have a smaller impact on

\footnotetext{
${ }^{11}$ This gap could be due to the characteristics of firms using the services of highly reputed banks, which could have better future
} 
stock prices of recommended firms. Reiterations of previous opinions should not affect prices significantly either pre- or post-MAD because they are not informative; see Womack (1996) and Clement and Tse (2005) among others. The corresponding hypothesis is expressed as follows.

$\mathrm{Hb} 1$ : Abnormal returns associated with post-MAD upgrades and positive initiations (downgrades and negative initiations) are higher (less negative) than abnormal returns associated with pre-MAD similar recommendations.

A higher investor protection should translate into higher stock price reactions because financial institutions bear higher costs for misleading recommendations.

$\mathrm{Hb}$ 2: Abnormal returns associated with pre-MAD upgrades and positives initiations (downgrades and negative initiations) are positively related to the level of investor protection.

The assumption underlying the adoption of MAD is that investors take all recommendations for granted. If investors were not aware of conflicts of interest pre-MAD, the stock price reaction to recommendations should be the same regardless of the issuer. This pattern should not change post-MAD since sources of potential conflicts are disclosed and misleading recommendations are under the scope of the regulation. However, if investors discounted misleading recommendations appropriately, they were not necessarily penalized prior to the adoption of MAD. In this setting, before MAD, we should not notice any difference in stock price reactions resulting from recommendations affected by conflicts or from those that are not. In the aftermath of MAD, as there is no need to discount recommendations, we should observe stronger stock price reactions for recommendations potentially affected by conflicts of interest.

prospects. 
$\mathrm{Hb} 3$ : Abnormal returns associated with favorable recommendations affected by conflicts of interest are higher post-MAD.

Since MAD was expected to reduce the risk of issuing optimistic recommendations, the comparative advantage of financial institutions with high reputation capital at stake should decrease post-MAD.

Hb4: Abnormal returns associated with upgrades and positive initiations (downgrades and negative initiations) emanating from highly reputed financial institutions are lower post-MAD.

\subsection{Research design}

In order to assess whether the adoption of MAD modified how investors interpret recommendations, we estimate Cumulative Abnormal Returns over a three-day period surrounding recommendation releases with the Market Model ${ }^{12}$; see Stickel (1995), Womack (1996), Salva and Sonney (2006) and Kadan, Madureira, Wang and Zack (2007) among others.

We estimate the following model to explain CARs:

$$
\begin{aligned}
\text { CAR }_{b, j, t}= & a_{0}+a_{1} \text { PostLaw }_{j, t}+a_{2} \text { PubEnf }_{j, t}+a_{3} \text { Conflicts }_{b, j, t}+a_{4} \text { Rep }_{b, t} \\
& +a_{5} \text { PostLaw }_{j, t} \times \text { Conflicts }_{b, j, t}+a_{6} \text { PostLaw }_{j, t} \times \text { Rep }_{b, t} \\
& +\mathbf{c}^{\prime} \times \text { Control } \mathbf{V a r}_{\mathbf{b}, \mathbf{j}, \mathbf{t}}+\varepsilon_{b, j, t}
\end{aligned}
$$

where PostLaw, PubEnf, Conflicts and Rep are the four dummies defined in the previous section. In addition to the variables of interest, the model includes the interactions of PostLaw with Conflicts and

12 The parameters are estimated over $[-250,-11]$ and corrected for infrequent trading as in Maynes and Rumsey (1993). According to Datastream conventions and following Lesmond, Ogden and Trzcinka (1999), we define a stock price as missing if the following conditions are fulfilled: a) the current stock price is equal to its previous value, b) trading volume is nil and c) the current value of the market index is different from its previous value. Non-working days are days for which the stock index is equal to its previous value. Returns are computed over two consecutive working days with non missing prices. Recommendations with missing prices at the beginning or the end of the $[-1,+1]$ period are excluded. 
$R e p^{13}$. We also introduce a set of control variables (ControlVar) aimed at measuring the quantity ("surprise") and the quality of information contained in recommendations. We also control for differences in the firm informational environment; see Gleason and Lee (2003), Ertimur et al. (2007) and Jegadeesh and Kim (2007) among others.

\subsection{Control variables ${ }^{14}$}

\subsubsection{Quantity of information}

We estimate the innovation conveyed by a recommendation as the spread of the current recommendation from its consensus, Dcons. The consensus is the average of the last recommendations issued by analysts. In order to incorporate recent information only, we eliminate recommendations older than six months. Recommendations strongly departing from other analysts' sentiment (consensus) are expected to bring more information to market participants relative to recommendations issued by analysts herding around the consensus; see Clement and Tse (2005) and Jegadeesh and Kim (2007). As these recommendations should induce a strong positive (negative) stock price reaction for upgrades (downgrades) and positive (negative) initiations ${ }^{15}$, we expect a positive (negative) association between Dcons and CAR.

A recommendation closely following a similar recommendation issued by another analyst should have a lower impact since its informational content was already, at least partially, incorporated into stock prices. We measure the timeliness of a recommendation using the number of recommendations for the

\footnotetext{
${ }^{13}$ The interaction Conflicts with Rep is not included the cross-product of Conflicts and Rep is exactly equal to Rep; see the definition of these variables above. The interaction of PostLaw and PubEnf is not included either because after the adoption of $\mathrm{MAD}$, the laws across EU are assumed to be closed.

${ }^{14}$ The definition of the control variables is summarized in Appendix 2.

15 As the explanatory variables are expected to have reverse signs for downgrades versus upgrades, we focus on upgrades and positive initiations only.
} 
same stock issued during the ten-day period preceding the recommendation. We expect a positive (negative) association between this variable, labeled Follow, and CAR.

\subsubsection{Information quality}

Large financial institutions have more resources to support research. This should contribute to more accurate forecasts and valuable recommendations; see Stickel (1995) and Clement (1999). Furthermore, large institutions hire skilled analysts which are less prone to herd; see Fang and Yasuda (2006). We rank financial institutions based on the number of recommendations they issued over the previous year. We define a dummy variable, BigBro $\mathrm{ker}_{b, t}{ }^{16}$, equal to one if the financial institution is in the first decile and zero otherwise. This variable is expected to be positively related to $C A R$.

A recommendation with a companion earnings forecast revision is likely to be more informative since it allows investors to infer the magnitude of the expected stock price revision. We measure the reliability of the recommendation, $\operatorname{Rel}_{b, j, t}$, using a dummy variable equal to one if an annual earnings forecast was issued by the same analyst during the ten-day period surrounding the recommendation and zero otherwise. Consequently, we expect a positive (negative) association between $R e l$ and $C A R$ for upgrades or positive initiations (downgrades or negative initiations).

\subsubsection{Information environment}

The information flow increases monotonically with the number of financial institutions following the firm; see Ertimur et al. (2007). The speed at which information is incorporated into stock prices is also positively related to analyst coverage; see Brennan, Chordia and Swaminathan (1993). Therefore, the

\footnotetext{
${ }^{16}$ Previous research defines use the number of analysts employed by the broker. This measure is unavailable in our study because there are Teams which number of analysts is not reported in $\mathrm{I} / \mathrm{B} / \mathrm{E} / \mathrm{S}$
} 
stock price reaction to a new recommendation should be inversely related to the number of financial institutions covering the firm. Hence, we expect a negative (positive) relation between CAR and coverage for upgrades (downgrades). We measure coverage with a Log transformation of the number of financial institutions having released recommendations on firm $j$ over the six-month period preceding the current recommendation.

Earnings announcement released during, or close to, the event window may induce analysts to revise their recommendations. In that setting, the causality between the recommendation and the stock price change does not result from gathering and processing independent information. We control for this spurious causality using a dummy variable, $C E R_{j, t}$, equal to one if the recommendation is “C"ontemporaneous to an "E"arnings "R"elease within the event window; see Ivkovic and Jegadeesh (2004), Boni and Womack (2006) and Sonney and Salva (2006). As upgrades (downgrades) occur mainly after positive (negative) earnings surprises, we expect a positive (negative) association between $C E R$ and CAR.

\subsection{Descriptive statistics}

\subsubsection{Initiations, reiterations and revisions}

Table 3 reports summary statistics of initiations, re-iterations, upgrades and downgrades and sub-totals sorted by year. As already mentioned, there is no clear break point in the structure of recommendations. Positive initiations represent 55 percent of initiations, while positive reiterations represent 48 percent of reiterations. Initiations dropped by 6.34 percent from 18.85 percent to 12.52 percent (z-stat $=-34.11$, significantly different from 0 at the 1 percent level). The requirement to announce when brokers decide to 
stop coverage could explain this decrease (CD2003/125/EC, Article 4.1.d). However, we cannot rule out two alternative explanations. The first possibility is that this drop could be related to the decrease in the number of IPOs in the aftermath of the "Internet Bubble". The second possibility relates to the reorganization of brokerage houses in Europe in the late nineties. During that period, financial institutions that had historically concentrated on their national markets initiated a more systematic coverage of all European firms. The result was an unusual number of initiations; see Sonney (2007).

$$
\text { Insert }<\text { Table } 3>\text { about here }
$$

In order to study whether recommendations are more informative under the new regulatory regime, we made a pre- and post-MAD comparison of the frequency of re-iterations and of recommendations issued simultaneously with an earnings forecast ${ }^{17}$. Consistent with more informative recommendations and effective anti-disclosure provisions, the proportion of re-iterations decreased by $2.47 \%$ from $20.73 \%$ to $18.25 \%$ (z-stat $=-12.60$, significantly different from 0 at the 1 percent level), while the proportion of contemporaneous recommendations increased by $0.62 \%$ (from $11.56 \%$ to $12.18 \%$; $z$-stat $=3.95$, significantly different from 0 at the 1 percent level) after MAD was passed. However, the proportion of recommendations that were not accompanied by an earnings forecast did not change significantly $(8.20 \%$ pre-MAD and $8.31 \%$ post-MAD, not statistically different at the 5 percent level).

\subsubsection{Cumulated abnormal returns around recommendations (CARs)}

Table 4 displays descriptive statistics of CARs. They are split by type of recommendations and by preMAD vs. post-MAD sub-periods. We first examine CARs that are statistically significant both pre-MAD

\footnotetext{
${ }^{17}$ We use a ten-day period around the publication of the recommendation to determine whether the recommendation was accompanied by an earnings forecast or not.
} 
and post-MAD. Abnormal stock price reactions to positive initiations and upgrades are higher and significantly more pronounced in the post-MAD period. Interestingly, stock price reaction to downgrades is also significantly stronger during the post-MAD period. Stock price reaction to neutral initiations, which was significantly negative pre-MAD, is no longer significant post-MAD. This result suggests that MAD rendered these recommendations more understandable. Stock price responses to negative reiterations are insignificant both before and after the adoption of MAD. However, the difference between them is marginally significant at the 5 percent level. The remaining CARs are not significantly different from 0 at the same level.

Insert $<$ Table $4>$ about here

These preliminary results are consistent with hypothesis $\mathrm{Hbl}$ which states that favorable recommendations should have higher returns in the post-MAD period. Returns associated with negative initiations are not statistically different across periods. However, returns associated with downgrades are significantly lower in the post-MAD period. This confirms our hypothesis that the impact of unfavorable recommendations decreases with increased reporting frequency. Note also that the CARs in this study are significantly higher than those reported in Jegadeesh and Kim (2004) for France, Great Britain, Germany and Italy. This discrepancy can be explained by the fact that we retain the day before recommendation release in the computation of CARs and, more importantly, by our more recent sample period (1997 to 2006), which includes the effects of MAD. 


\subsection{The impact of MAD on stock price reactions to recommendations}

\subsubsection{Main results}

Since abnormal returns induced by upgrades, positive initiations and downgrades are highly significant and exhibit significant differences pre-MAD and post-MAD, we restrict our analysis to these recommendations ${ }^{18}$.

Insert $<$ Table $5>$ about here

In Table 5, we first examine how stock price response to recommendations changed after MAD. Consistent with our hypothesis $\mathrm{Hb} 1$, we find that the adoption of MAD had a strong positive (negative) impact on upgrades and positive initiations (downgrades). The impact of MAD on abnormal returns comes to $0.37 \%$ or $0.45 \%$ depending on the type of conflict of interest under consideration $(C M A D$ or $C I B)$. It is both statistically and economically highly significant.

We turn our attention to cross-border investor protection and its impact on stock market reactions to recommendations. The coefficient of PubEnf is significant at the 1 percent level for upgrades and for both measures of conflicts (Hb2). An increase of 50 basis points in PubEnf (corresponding to the difference between Great Britain (highest) and Austria (lowest)) results in an increase in CAR of 0.13 percent. For positive initiations, the impact of PubEnf is of a similar magnitude and is (not) significant at the 5 percent level for $C I B(C M A D)$. For downgrades, PubEnf is never significant at the usual levels. Jegadeesh and Kim (2006) attribute the differences in stock price reactions to recommendations between the US and four EC countries (France, Germany, Italy and UK) to US analyst skills. Our results show that investor protection explains, at least partly, these differences. 
A significant part of MAD (CD125/2003/EC) was dedicated to curbing conflicts of interest. Our results show that conflicts $(C M A D / C I B)$ did not have an impact on CARs associated with upgrades before MAD, leaving us with the following options. Either investors were completely unaware of conflicts or they discounted recommendations appropriately. Since the market reaction to upgrades is positive and significant (at the 5 percent level) post-MAD, we conclude that investors discounted pre-MAD recommendations issued by investment banks. However, this result does not hold for underwriters. Investors reacted negatively pre-MAD, and still react negatively post-MAD (one-side tests are significant at the 5 percent level) to downgrades that are potentially affected by conflicts, showing that they interpret these recommendations as "very bad" news. This result is also consistent with the idea that investors know and understand that investment banks and underwriters have no interest is releasing downgrades.

The last hypothesis (Hb4) concerns reputation (Rep). The corresponding coefficients are all significant at the 1 percent level. Investors give more value to recommendations issued by investment banks with a high reputation at stake indicating that investors are well aware of potential conflicts. As expected, the adoption of MAD reduced the comparative advantage of financial institutions with high reputations. CARs associated with downgrades (upgrades) are significantly less negative (positive) at the 5 percent level and are statistically insignificant at the same level. Concerning positive initiations, reputation has a positive impact (significant at the 5 percent level with $C M A D$, insignificant with $C I B$ ), which contradicts our hypothesis.

The control variables provide some interesting and new insights into European Markets. Empirical evidence in Jegadeesh and Kim (2006) suggests that European markets react less to recommendations than

\footnotetext{
${ }^{18}$ Results for reiterations and for neutral and negative recommendations are available upon request.
} 
US markets. We find that CARs in Europe, albeit smaller than their US counterparts, are explained by similar variables. These variables are all highly significant (at the 1 percent level) for both upgrades and downgrades. They all have the expected sign. Moreover, they are insensitive to the definition of conflict on interest.

\subsubsection{Robustness check}

As already explained, there are at least two other dates to consider with regard to the adoption of MAD. The first date is the adoption of the Commission Directives (December $23^{\text {rd }}, 2003$ ) and the second date is the deadline by which EC countries had to transpose MAD into their national laws (October $\left.12^{\text {th }}, 2004\right)$. In order to check the robustness of our results with respect to these dates, we define two dummy variables. These are respectively equal to one after the adoption of the Commission Directive (PostEC) and after the transposition deadline (PostDL), and zero otherwise. Based on the variables PostLaw, PostEC and PostDL, we define three non-nested models. We compare these models using the Davidson and McKinnon (1981) procedure. The results are presented in Table 6.

$$
\text { Insert }<\text { Table } 6>\text { about here }
$$

No model clearly dominates in all aspects. In particular, the model with PostEC has additional explanatory power compared to the one with PostLaw, and vice-versa. In other words, CARs changed prior to the transposition of MAD into national law(s). There are several reasons for that. First, some brokers could have decided to adopt the provisions of MAD as soon as the law was passed in their own country. Others could have adopted these provisions as soon as they were made public, notably because some provisions were already part of codes of ethics issued by professional associations. Finally, the US regulation could have spilled-over into the EC (see below). All these models provide similar results in 
term of significance of the explanatory variables, confirming the robustness of our results. The model initially estimated with PostLaw has extra explanatory power as compared to the ones based on PostEC and PostDL.

\subsection{Why did abnormal returns increase after all?}

As shown in Section 3.1., RegFD induced no global change in US stock price reactions to recommendations. However, as already mentioned, the corresponding provisions of MAD (CD124/2003/EC) could have had a negative impact on recommendations issued by underwriters who had insider knowledge of the firms; see Cornett et al. (2007). These financial institutions are more exposed than others to a loss of their informational advantage for at least two reasons. First, the adoption of MAD led the Management of recommended firms to eliminate selective disclosures. Second, reorganization of their financial research and investment banking departments made obtaining private information difficult (Chinese wall). Therefore, positive recommendations and upgrades issued by financial institutions with investment banking ties with the recommended firm are expected to convey less private information postMAD and, consequently, the stock price reaction should be lower.

To check this hypothesis, we estimate our model for the sub-set of favorable recommendations ("Buy", "Strong Buy" and upgrades) issued by financial institutions exposed to conflicts of interest as defined by the provisions of MAD $(C M A D=1)$. The sum of the coefficients (similar to previous hypothesis $\mathrm{H} 1 \mathrm{~b})$ is 0.23 percent $(\mathrm{t}$-stat $=0.46)$ for upgrades, 0.11 percent $(\mathrm{t}$-stat $=0.37)$ for positive initiations and 0.43 percent $(\mathrm{t}$-stat $=0.39)$ for positive reiterations. All the coefficients being statistically insignificant, we reject this hypothesis. Therefore, given results in section 6.3.1., it appears that two main factors caused the 
change in CARs. First, conflicts of interest, if not completely curbed by MAD, were reduced. Second, the fair presentation of recommendations, which is almost costless to implement, played also a role.

\section{US regulation spill-over onto EC recommendations}

The third question addressed in this research is whether the adoption of MAD was really necessary insofar as a similar regulation had been adopted more than two years earlier in the US.

\subsection{Hypotheses}

Until now, we have assumed that recommendations are only influenced by the regulations of the country in which recommended stocks are listed. Implicitly, this is equivalent to assuming that national regulations are only oriented toward local markets. However, European banks that have important stakes in the US ${ }^{19}$, as well as US banks following European firms, do not restrict the diffusion of their reports to EC countries. US and European financial institutions with their headquarters, a branch, a subsidiary or that simply do business in the US (hereafter global banks), must comply with US regulations when they release reports directed toward US investors ${ }^{20}$; see Becker, Yim and Greenawalt (1999). These financial institutions do not consider the nationality of the recommended firm or of the potential recipients of their analysts' reports. These analysts' reports reflect regulatory changes as soon as they are adopted, and thus we hypothesize that US regulations immediately affect recommendations on stocks listed on EC markets.

\footnotetext{
${ }^{19}$ Deutsche Bank was part of the Global Research Settlement.

${ }^{20}$ Anecdotal evidence shows that recommendations sent to costumers on a regular basis included information on conflicts of interest well before the CD 2003/125/EC was passed. Recommendations of non-US stocks released by UBS for US costumers mentioned investment banking business as soon as the second semester of 2002. Société Générale released these conflicts as early as the beginning of 2003 .
} 
In order to analyze whether the US regulations devoted to anti-selective disclosure and analysts' conflicts of interest spilled over on to recommendations issued by global banks on European firms, we restrict our analysis to two sub-periods. The pre-US regulation period begins on January $1^{\text {st }}, 1998$ and ends with the adoption of RegFD on October $23^{\text {rd }}, 2000$. The post-US regulation period begins with the adoption of NASD Rule 2711 and NYSE Rule 472 of November $6^{\text {th }}, 2002$. It ends on December $23^{\text {rd }}$, 2003 with the adoption of CD 2003/124/EC and CD 2003/125/EC. The intervening period is excluded from our analysis since, as Ertimur et al. (2007, p. 582) argue, "it represents a transition period in terms of information environment and is characterized by market-wide volatility". Thus, if the US regulation had any effect, we should observe a difference in the distribution of recommendations and in abnormal returns associated with these recommendations when comparing the two sub-periods and focusing on financial institutions operating both in the US and in the EC. We express our set of hypotheses as follows.

Hc1: The proportion of positive (negative) recommendations on EC stocks issued by global banks did not change after the adoption of the US regulations.

Hc2: Abnormal returns associated with upward (downward) revisions on EC stocks issued by global banks did not change after the adoption of the US regulations.

\subsection{Results}

We first examine the change in the distribution of recommendations to determine how global banks reacted to the adoption of the US regulations. We observe a dramatic drop in the proportion of positive recommendations from 51.57 percent to 40.95 percent $(\mathrm{z}$-stat $=-28.43)$ and an increase of similar magnitude in the proportion of negative recommendations from 13.53 percent to 22.23 percent $(z$-stat $=30.99)$ for the sub-sample of global banks. For the remaining local banks, not directly concerned 
by the US regulations, the magnitude of the drop (increase) is smaller but, nevertheless, also significant. The proportion of positive recommendations dropped from 49.06 percent to 46.22 percent $(z$-stat $=-5.33)$ and the proportion of negative recommendations increased from 16.77 percent to 21.76 percent (z-stat $=12.02)$. Therefore, we strongly reject $\mathrm{Hcl}$ at the usual level of confidence. The decrease (increase) in positive (negative) recommendations shows that all financial institutions and more specifically those that had to comply with the US regulations changed the distribution of their recommendations on EC stocks after the adoption of these regulations. Because of the spill-over of the US regulations, changes in European recommendations materialized well before the adoption of the EC Commission Directives.

The remaining question is whether and how investors interpreted these significant changes in the distribution of recommendations. In response, we estimate a model similar to the previous one. However, four differences are noteworthy. First, we restrict our sample period to the pre- and post-US regulation periods. Second, we examine separately the sample of "Global Banks" that had to comply with the US regulations from those that did not (i.e. "Local Banks"). Third, we do not control for conflicts of interest and reputation since our investigation is limited to the impact of the US regulation on European recommendations. Fourth, and most importantly, we do not include a variable capturing differences in terms of enforcement between countries since we focus only on the US regulation.

We estimate the following model:

$$
C A R_{b, j, t}=a_{0}+a_{1} \operatorname{Post} U S \operatorname{Re} g_{t}+\mathbf{c}^{\prime} \times \operatorname{Control} \operatorname{Var}_{\mathbf{b}, \mathbf{j}, \mathbf{t}}+\varepsilon_{b, j, t}
$$

PostUSReg is a dummy variable equal to one for recommendations issued between November $6^{\text {th }}, 2002$ and December $23^{\text {rd }}, 2003$, and is zero otherwise. The null hypothesis is that the US regulations had no 
effect on recommendations issued on EC stocks. Table 7 reports the coefficients and the corresponding tstats.

$$
\text { Insert }<\text { Table } 7>\text { about here }
$$

Hc2 is neither rejected for upgrades nor for downgrades issued by global banks. Concerning "positive initiations", and contrary to our hypothesis, the coefficient associated with PostUSReg is negative. It is possible that this finding is sample specific given the poor performance of European stock markets and the low number of IPOs that took place during that period.

In counterpoint, local banks constitute an interesting case study since they are not directly concerned by the US regulations under consideration. As expected, we do not find any significant change in the stock price reaction to upgrades and positive initiations. However, the coefficient of PostUSReg is positive and significant at the one percent level for downgrades. The market reaction to downgrades issued by local banks is less negative than reactions prior to the adoption of the US regulations. Negative recommendations could have been perceived less negatively during that period (bear market), in particular if local banks were late in incorporating bad news already known by market participants.

To summarize, we find strong evidence that financial institutions reduced (increased) the proportion of favorable (unfavorable) recommendations after the US regulations were passed. Nevertheless, investors did not react significantly to these changes until MAD was adopted. Consistent with improved investor protection that accompanied the adoption of MAD, CARs did not change systematically until the law was passed. Thus, we conclude that the US regulations did not completely spill over into the European stock markets. 


\section{Conclusion}

Since 2000, new regulations aimed at curbing selective disclosure and conflicts of interest in the financial analyst profession have been adopted in the US. Similar regulations, known as MAD, were passed in the EC. The empirical evidence reported in this paper is in sharp contrast with previous literature. While the distribution of US recommendations changed dramatically following the adoption of the US regulations, we document a smaller impact on the distribution of EC recommendations after the adoption of MAD.

These findings raise the following question: Was the EC regulation necessary and/or effective?

To answer this question, we examined the impact of MAD on the distribution of recommendations and stock price reactions following recommendation releases, controlling for the nature of conflicts of interest and the intensity of investor protection.

We used two definitions of conflicts of interest. First, following MAD, a recommendation was said to be at risk of conflicts if it was issued by a financial institution that had business ties with the recommended firm during the previous twelve months. Under this definition, recommendations potentially affected by conflicts of interest represented less than $2 \%$ of the total. Second, we used a more conventional definition of conflicts. Under this definition, a recommendation suffers from a potential conflict of interest if it is issued by a financial institution with investment banking business during the previous year, independent of the firms concerned by the recommendation. Using the second definition, the proportion of conflicted recommendations increases dramatically to more than $60 \%$ of the total. This figure is more in line with what was observed in the US at $80 \%$ of the total. The shape of the distribution changed post-MAD since positive recommendations became less frequent. 
Concerning market reaction to recommendations, we analyzed revisions and initiations, since both of these are expected to convey more information than mere reiterations. We found that MAD had a significant impact on positive upgrades, which suggests that the adoption of MAD increased upgrade recommendation credibility for investors. Interestingly, this effect did not result in less credible downgrades. In fact, the introduction of MAD has had a negative impact on stock price reactions to downgrades, suggesting increased credibility.

Differences in investor protection, as defined by La Porta et al. (2006), are also highly significant. Securities laws were at very different developmental levels within the EC prior to the adoption of MAD. After MAD these differences were greatly diminished. Our findings show that investor protection is an important determinant of stock price reaction to recommendations. They also show that investors react more strongly to recommendations when potential conflicts of interest related to investment banking business are revealed. Furthermore, reputation acts as a strong deterrent of conflicts and the adoption of regulations had no impact on it.

Finally, we examined whether the US regulation spilled over into the EC, making the EC directive redundant. Our results show that financial institutions dramatically changed the distribution of their recommendations (fewer positive recommendations and more negative recommendations) following the adoption of the US regulations. However, investors reacted to this change only after MAD was adopted. Therefore, MAD was legitimate, not because it changed analysts' behavior but because it reassured investors that the law was enforceable. 


\section{References}

Agrawal, A., Chadha, S., Chen, M., 2006. Who is Afraid of Reg FD? The behavior and performance of sell-side analysts following the SEC's Fair Disclosure Rules. Journal of Business 79, 2811-2834.

Agrawal, A., Chen, M., 2008. Do Analyst Conflicts Matter? Evidence from stock recommendations. Journal of Law and Economics, forthcoming.

Bailey, W., Li, H., Mao, C., Zhong, R., 2003. Regulation Fair Disclosure and earnings information: market, analyst, and corporate responses. Journal of Finance 58, 2487-2514.

Barber, B., Lehavy, R., McNichols, M., Trueman, B., 2001. Can investors profit from the prophets? Security analyst recommendations and stock returns. Journal of Finance 56, 531-563.

Barber, B., Lehavy, R., Trueman B., 2007. Comparing the stock recommendation performance of investment banks and independent research firms. Journal of Financial Economics 85, 490-517.

Becker, B., Yim, S., Greenawalt, A., 1999. A regulatory dilemma: electronic access to foreign markets. Wallstreetlawyer.com 3-3, 1-8.

Belcredi, M., Bozzi, S., Rigamonti, S., 2003. The impact of research reports on stock prices in Italy. SSRN: http://ssrn.com/abstract $=391680$

Bolliger, G., 2004. The characteristics of individual analysts' forecasts in Europe. Journal of Banking and Finance 28, 2283-2309.

Bolton, P., Freixas X., Shapiro J., 2007. Conflicts of interest, information provision, and competition in the financial services industry. Journal of Financial Economics 85, 297-330.

Bradley, D., Jordan, B., Ritter, J., 2007. Analyst behaviour following IPOs: the "Bubble Period" evidence. Review of Financial Studies 21, 101-133.

Brennan, M., Jegadeesh, N. Swaminathan, B., 1993. Investment analysis and the adjustment of stock prices to common information. Review of Financial Studies 6, 799-824.

Brown, L., 2001. How important is past analyst forecast accuracy?. Financial Analysts Journal 57, 44-49.

Brown, S., Hillegeist, S., Lo, K., 2004. Conference calls and information asymmetry. Journal of Accounting and Economics 37, 343-366.

Clarke, J., Khorana, A., Patel, A., Rau, P., 2007. The impact of All-Star analyst job changes on their coverage choices and investment banking deal flow. Journal of Financial Economics, 84, 713-737.

Clement, M., 1999. Analyst Forecast Accuracy: Do Ability, Resources, and Portfolio Complexity Matter? Journal of Accounting and Economics 27, 285-303.

Clement, M., Rees L., Swanson E., 2003. The influence of culture and corporate governance on the characteristics that distinguish superior analysts. Journal of Accounting, Auditing and Finance 18, 593-618. 
Clement, M., Tse, S., 2003. Do investors respond to analysts' forecast revisions as if forecast accuracy is all that matters? Accounting Review 78, 227-249.

Clement, M., Tse, S., 2005. Financial analyst characteristics and herding behavior in forecasting. Journal of Finance 60, 307-341.

Cliff, T., 2004. Do independent analysts provide superior stock recommendations? SSRN: http://ssrn.com/abstract=540123.

Cooper, R., Day T., Lewis, C., 2001. Following the leader: a study of individual analysts earnings forecasts, Journal of Financial Economics 61, 383-416.

Cornett, M., Tehranian, H., Yalcin, A., 2007. Regulation fair disclosure and the market's reaction to analyst investment recommendation changes. Journal of Banking and Finance 31, 567-588.

Cowen, A., Groysberg B., Healy P., 2006. Which types of analyst firms make more optimistic forecasts? Journal of Accounting and Economics 41, 119-146.

Davidson, R., Mc Kinnon, J., 1981. Several tests for model specification in the presence of alternative hypotheses. Econometrica 49, 781-793.

Dechow, P., Hutton A., Sloan R., 2000. The relation between analysts' forecast of long-term earnings growth and stock price performance following equity offerings. Contemporary Accounting Review $17,1-32$.

Dimson, E., Marsh, P., 1984. An analysis of brokers' and analysts' unpublished forecasts of UK stock returns. Journal of Finance 39, 1257-1292.

Duarte, J., Han, X., Harford, J., Young, L., 2008. Information asymmetry, information dissemination and the effect of regulation FD on the cost of capital. Journal of Financial Economics 87, 24-44.

Dubois, M., Dumontier, P., 2006. Do conflicts of interest affect analysts' forecasts and recommendations? A survey. In: Thévenoz, L., Bahar R. (Eds.), Conflicts of interest, corporate governance and financial markets. Kluwer Law International, 187-210.

Dugar, A., Nathan, S., 1995. The effect of investment banking relationships on financial analysts' earnings forecasts and investment recommendations. Contemporary Accounting Research 12, 131-160.

Eleswarapu, V., Thompson R., Venkataraman, K. 2004. The impact of Regulation Fair Disclosure: trading costs and information asymmetry. Journal of Financial and Quantitative Analysis 39, 209-225.

Elton, E., Gruber, M., Gultekin, M., 1984. Professional expectations: accuracy and diagnosis of errors. Journal of Financial and Quantitative Analysis 19, 351-363.

Enriques L., 2005. Conflicts of interest in investment services: the price and uncertain impact of MiFID's regulatory framework. SSRN: http://ssrn.com/abstract=782828.

Ertimur, Y., Sunder, J., Sunder, S., 2006. Measure for measure: the relation between forecast accuracy and recommendation profitability of analysts. Journal of Accounting Research 45, 567-606. 
Fang, L., Yasuda, A, 2005. Are stars' opinion worth more? The relation between analyst reputation and recommendations values. SSRN: http://ssrn.com/abstract=687491

Ferrarini, G., 2004. The European Market Abuse Directive. Common Law Market Review 41, 711-741.

Ferreira, E., Smith, S., 2006. Effect of Reg FD on information in analysts' rating changes. Financial Analysts Journal 62 n³, 44-57.

Francis, J., Soffer, L., 1997. The relative informativeness of analysts' stock recommendations. Journal of Accounting Research 35, 193-211.

Freshfields, Bruckhaus, Deringer, 2006. Market Abuse Directive (2003/6/EC). http://www.freshfields.com/publications/pdfs/2006/13447.pdf

Gleason, C., Lee, C., 2003. Analyst forecast revisions and market price discovery. Accounting Review 78, $193-225$.

Gomes, A., Gorton, G., Madureira, L., 2007. SEC Regulation Fair Disclosure, information, and the cost of capital. Journal of Corporate Finance 13, 300-334.

Greene, E., 2007. Resolving regulatory conflicts between the capital markets of the United Sates and Europe. Capital Markets Law Journal 2, 5-40.

Guay, W., Haushalter, D., Minton, B., 2003. The influence of corporate risk exposures on the accuracy of earnings forecasts. SSRN: http://ssrn.com/abstract $=375740$

Hansen, J., 2004. MAD in a hurry: The swift and promising adoption of the EU Market Abuse Directive. European Business Law Review 15, 183-221.

Hayes, R., 1998. The impact of trading commissions incentives on analysts' stock coverage decisions and earnings forecasts. Journal of Accounting Research 36, 299-320.

Heflin, F., Subramanyam, K., Zhang, Y. 2003. Regulation FD and the financial information environment: early evidence. Accounting Review 78, 1-37.

Hong, H., Kubik, J., 2003. Analyzing the analysts: career concerns and biased earnings forecasts. Journal of Finance 58, 313-351.

Hong, H., Kacperczyk, M., 2007. Competition and bias. http://finance.sauder.ubc.ca/ $\sim$ mkacpe/Index/bias.pdf

Irvine, P., 2001. Do analysts generate trades for their firms? Evidence from the Toronto stock exchange. Journal of Accounting and Economics 30, 209-226.

Ivkovich, Z., Jegadeesh N., 2004. The timing and value of forecast and recommendation revisions. Journal of Financial Economics 73, 433-463.

Jacob, J., Lys, T., Neale, M., 1999. Expertise in forecasting performance of security analysts, Journal of Accounting Economics 28, 51-82.

Jacob, J., Rock, S., Weber, D., 2007. Do non-investment bank analysts make better earnings forecasts? Journal of Accounting, Auditing and Finance, Forthcoming. 
Jackson, A., 2005. Trade generation, reputation and sell-side analysts. Journal of Finance 60, 673-717.

James, C., Karceski, J., 2006, Strength of analyst coverage following IPOs. Journal of Financial Economics 81, 1-34.

Jegadeesh, N., Kim, W., 2006. Value of analyst recommendations: International evidence. Journal of Financial Markets 9, 274-309.

Jegadeesh, N., Kim, W., 2007. Do analysts herd? An analysis of recommendations and market reactions. SSRN: http://ssrn.com/abstract $=957192$

Jegadeesh, N., Kim, J., Krische, S., Lee C., 2004. Analyzing the analysts: When do recommendations add value? Journal of Finance 59, 1083-1124.

Kadan, O., Madureira, L., Wang, R., Zach, T., 2007. Conflicts of interest and stock recommendations The effects of the global settlement and related regulations. SSRN: http://ssrn.com/abstract $=568884$

Kolasinski, A., Kothari, S., 2007. Investment Banking and Analyst Objectivity: Evidence from Analysts Affiliated With M\&A Advisors. Journal of Financial and Quantitative Analysis, Forthcoming. SSRN: http://ssrn.com/abstract=499068

Lesmond, D., Ogden, J., Trzcinka, C., 1999. A new estimate of transaction costs. Review of Financial Studies 12, 1113-1141.

Lim, T., 2001. Rationality and analysts' forecast bias. Journal of Finance 56, 369-385.

Lin, H., McNichols, M., 1998. Underwriting relationships, analysts' earnings forecast and investment recommendations. Journal of Accounting and Economics 25, 101-127.

Ljungqvist, A., Marston F., Starks, L., Wei K., Yan, H., 2005. Conflicts of Interest in Sell-side Research and the Moderating Role of Institutional Investors. Journal of Financial Economics 85, 420-456.

Ljungqvist, A., Marston, F., Wilhelm, W., 2006. Competing for securities underwriting mandates: banking relationships and analyst recommendations. Journal of Finance 61, 301-340.

Loh, R., Mian, M., 2006. Do accurate earnings forecasts facilitate superior investment recommendations? Journal of Financial Economics 80, 455-483.

McNichols, M., O’Brien, P., 1997. Self-selection and analyst coverage. Journal of Accounting Research 35, 167-199.

McNichols, M., O’Brien, P., Pamukcu, O., 2006. That ship has sailed: unaffiliated analysts' recommendation performance for IPO firms. SSRN:

http://ssrn.com/abstract $=892633$

Malmendier, U., Shanthikumar D., 2007. Are small investors naive about incentives? Journal of Financial Economics 85, 457-489.

Malmendier, U., and Shanthikumar, D., 2007b. Do security analysts speak in two tongues? Working Paper, http://www.econ.berkeley.edu/ ulrike/ 
Maynes, E., Rumsey, J., 1993. Conducting event studies with thinly traded stocks. Journal of Banking and Finance 17, 145-157.

Mehran, H., Stulz, R., 2007. The economics of conflicts of interest in financial institutions. Journal of Financial Economics 85, 267-296.

Michaely, R., Womack, K., 1999. Conflict of interest and the credibility of underwriter analysts' recommendations. Review of Financial Studies 12, 653-686.

Mikhail, M., Walther B., Willis, R., 1999. Does forecast accuracy matter to security analysts? Accounting Review 74, 185-200.

Mikhail, M., Walther B., Willis, R., 2007. When analysts talk, who listens? Accounting Review 82, $1227-$ 1253.

Mohanram, P., Sunder, S., 2006. How has Regulation FD affected the operations of financial analysts? Contemporary Accounting Research 23, 491-525.

Mola, S., 2005. Do IPO analysts issue unfavourable recommendations on non-IPO firms? Working Paper, Purdue university.

Mulherin, J., 2007. Measuring the costs and benefits of regulation: conceptual issues in securities markets. Journal of Corporate Finance 13, 421-437.

O'Brien, P., 1988. Analysts' forecasts as earnings expectations. Journal of Accounting and Economics 10, 53-83.

O'Brien, P., McNichols, M., Lin H., 2005. Analyst impartiality and investment banking relationships. Journal of Accounting Research 43, 623-650.

Petersen, M., 2007. Estimating standard errors in finance panel data sets: comparing approaches. Review of Financial Studies forthcoming.

Puckett, A., Lipson M., 2004. Are lead analysts really optimistic? Working Paper, University of Georgia Athens (USA).

Stickel, S., 1992. Reputation and performance among security analysts. Journal of Finance 46, 3-27.

Salva, C., Sonney, F., 2006. The value of analysts' recommendations and the organization of financial research. SSRN: http://ssrn.com/abstract $=892569$

Sette, E., 2007. Competition and opportunistic advice of financial analysts: theory and evidence. http://personal.lse.ac.uk/sette/research1.htm

Sonney F., 2007. Financial Analysts' Performance: Sector versus Country Specialization. Review of Financial Studies, forthcoming. http://rfs.oxfordjournals.org/papbyrecent.dtl

Stickel, S., 1995. The anatomy of the performance of buy and sell recommendations. Financial Analysts Journal 51, 25-39.

Sunder, S., 2003. Investor access to conference call disclosures: Impact of Regulation Fair Disclosure on information asymmetry. SSRN: http://ssrn.com/abstract=298653 
Dubois-Dumontier - Regulating the Financial Analysis Industry: Is the European Directive Effective?

Yasuda, A., Fang, L., 2006. The effectiveness of reputation as a disciplinary mechanism in sell-side research. SSRN: http://ssrn.com/abstract $=587961$

Womack, K., 1996. Do brokerage analysts' recommendations have investment value? Journal of Finance $51,137-167$. 
Dubois-Dumontier - Regulating the Financial Analysis Industry: Is the European Directive Effective?

\section{Table 1: Descriptive statistics of recommendations}

This table reports summary statistics of recommendations issued by brokers over the 1998-2007 period. Panel A (B) reports the information sorted by country (year). Column 1 and column 2 indicate the number of firms by country (year), respectively brokers, that appeared in the sample. Column 3 show the number of recommendations by country (year). Columns 4 to 8 show the number of recommendations by level (Strong Buy, Buy, Neutral, Sell, Strong Sell).

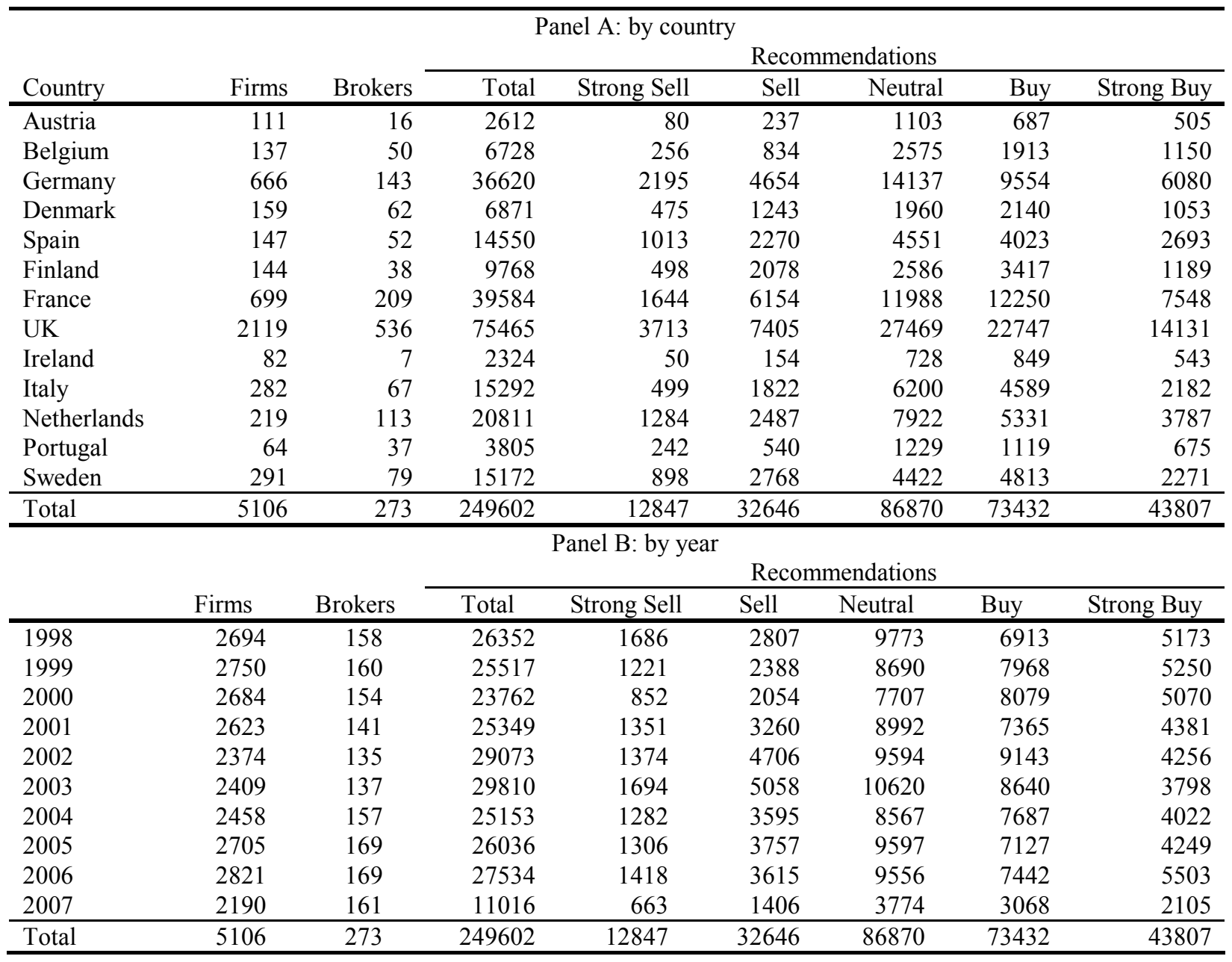


Table 2: MAD and the proportion of favorable and unfavorable recommendations

\begin{tabular}{|c|c|c|c|c|c|c|c|c|}
\hline \multicolumn{9}{|c|}{ Panel A: Unconditional change } \\
\hline & \multicolumn{4}{|c|}{ Unfavorable } & \multicolumn{4}{|c|}{ Favorable } \\
\hline Before & \multicolumn{4}{|c|}{18.12} & \multicolumn{4}{|c|}{47.22} \\
\hline After & \multicolumn{4}{|c|}{18.63} & \multicolumn{4}{|c|}{46.03} \\
\hline Diff. & \multicolumn{4}{|c|}{0.51} & \multicolumn{4}{|c|}{-1.19} \\
\hline Z-stat & \multicolumn{4}{|c|}{2.71} & \multicolumn{4}{|c|}{-4.89} \\
\hline \multicolumn{9}{|c|}{ Panel B: Enforcement } \\
\hline & \multicolumn{4}{|c|}{ Unfavorable } & \multicolumn{4}{|c|}{ Favorable } \\
\hline & \multicolumn{3}{|c|}{ Medium } & Low & High & \multicolumn{2}{|c|}{ Medium } & Low \\
\hline Before & \multicolumn{3}{|c|}{20.33} & 18.27 & 49.90 & \multicolumn{2}{|c|}{45.78} & 42.86 \\
\hline After & \multicolumn{3}{|c|}{22.03} & 17.16 & 46.63 & \multicolumn{2}{|c|}{46.43} & 44.38 \\
\hline Diff. & \multicolumn{3}{|c|}{1.70} & -1.11 & -3.27 & \multicolumn{2}{|c|}{0.66} & 1.53 \\
\hline z-stat & \multicolumn{3}{|c|}{2.35} & -1.15 & -6.02 & \multicolumn{2}{|c|}{1.08} & 1.95 \\
\hline \multicolumn{9}{|c|}{ Panel C: Conflicts of interest } \\
\hline & \multicolumn{4}{|c|}{ Unfavorable } & \multicolumn{4}{|c|}{ Favorable } \\
\hline & $C M A D=0$ & $C M A D=1$ & Diff. & Z-stat & $C M A D=0$ & $C M A D=1$ & Diff. & z-stat \\
\hline Before & 18.32 & 7.08 & 11.24 & 17.02 & 46.96 & 62.07 & -15.12 & -17.66 \\
\hline After & 18.84 & 8.87 & 9.98 & 8.55 & 45.83 & 55.31 & -9.48 & -6.35 \\
\hline Diff. & 0.53 & 1.79 & & & -1.13 & -6.76 & & \\
\hline \multirow[t]{2}{*}{ Z-stat } & 1.19 & 0.57 & & & -3.11 & -3.05 & & \\
\hline & $C I B=0$ & $C I B=1$ & Diff. & Z-stat & $C I B=0$ & $C I B=1$ & Diff. & z-stat \\
\hline Before & 18.96 & 17.63 & 1.32 & 7.33 & 44.89 & 48.57 & -3.68 & -15.73 \\
\hline After & 20.53 & 16.96 & 3.56 & 10.53 & 45.17 & 46.79 & -1.62 & -3.74 \\
\hline Diff. & 1.57 & -0.67 & & & 0.28 & -1.78 & & \\
\hline z-stat & 2.42 & -1.11 & & & 0.51 & -3.71 & & \\
\hline & & & & nel D: Repu & tion & & & \\
\hline & & Unfa & vorable & & & $\mathrm{Fav}$ & rable & \\
\hline & $R e p=0$ & $\operatorname{Rep}=1$ & Diff. & z-stat & $R e p=0$ & $\operatorname{Rep}=1$ & Diff. & z-stat \\
\hline Before & 19.62 & 13.08 & 6.54 & 31.67 & 48.17 & 44.05 & 4.12 & 15.39 \\
\hline After & 19.26 & 15.62 & 3.64 & 8.14 & 47.76 & 37.72 & 10.04 & 17.53 \\
\hline Diff. & -0.36 & 2.54 & & & -0.41 & -6.33 & & \\
\hline Z-stat & -0.75 & 2.52 & & & -1.05 & -6.94 & & \\
\hline
\end{tabular}


Dubois-Dumontier - Regulating the Financial Analysis Industry: Is the European Directive Effective?

\section{Table 3: Descriptive statistics of initiations and revisions}

This table reports summary statistics of recommendations issued by brokers over the 1998-2007 period. Columns 1 to 8 indicate the number of recommendations corresponding to initiating coverage, re-iterations, upgrades, and downgrades.

\begin{tabular}{cccccccccc}
\hline & \multicolumn{3}{c}{ Initiation } & \multicolumn{3}{c}{ Re-iteration } & Downgrades & Upgrades & Total \\
\cline { 2 - 7 } Year & Negative & Neutral & Positive & Negative & Neutral & Positive & & & \\
\hline 1998 & 1140 & 2956 & 4106 & 350 & 1076 & 1576 & 8043 & 7105 & 26352 \\
1999 & 751 & 1976 & 3572 & 404 & 1805 & 2296 & 6932 & 7781 & 25517 \\
2000 & 501 & 1416 & 3021 & 490 & 1892 & 3533 & 6848 & 6061 & 23762 \\
2001 & 728 & 1630 & 2546 & 505 & 1634 & 2903 & 9019 & 6384 & 25349 \\
2002 & 702 & 962 & 1811 & 1044 & 3069 & 3817 & 9393 & 8275 & 29073 \\
2003 & 671 & 1191 & 1899 & 1370 & 3331 & 2736 & 10215 & 8397 & 29810 \\
2004 & 588 & 1105 & 2243 & 765 & 1852 & 2249 & 8286 & 8065 & 25153 \\
2005 & 470 & 944 & 2015 & 941 & 2375 & 2167 & 8975 & 8149 & 26036 \\
2006 & 470 & 961 & 2241 & 675 & 1689 & 2086 & 9814 & 9598 & 27534 \\
2007 & 142 & 259 & 677 & 271 & 532 & 984 & 4255 & 3896 & 11016 \\
Total & 6163 & 13400 & 24131 & 6815 & 19255 & 24347 & 81780 & 73711 & 249602 \\
\hline
\end{tabular}




\section{Table 4: Cumulated Abnormal Returns (in \%) around initiations and revisions}

This table reports the Cumulated Abnormal Returns around initiations and revisions of recommendations from 1998 to 2007. CARs are computed over $[-1 ;+1]$ using the market model which parameters are estimated over $[-250 ;-11]$. Column $2(3)$ reports the CARs before (after) the adoption of MAD, Column 4 reports the difference between column 2 and column 3 and column 5 reports the t-stat corresponding to the null hypothesis of no difference between CARs pre and post MAD. Revisions issued contemporaneously are counted as one revision. Figures significant at the $1 \%(5 \%)$ level are in bold (italic) characters.

\begin{tabular}{|c|c|c|c|c|}
\hline & Pre-MAD & Post-MAD & Diff. & t-stat \\
\hline \multicolumn{5}{|l|}{ 1. Initiation } \\
\hline - Negative & -0.20 & -0.20 & 0.00 & 0.02 \\
\hline - Neutral & -0.22 & 0.03 & 0.25 & 3.01 \\
\hline - $\quad$ Positive & 0.33 & 0.83 & 0.51 & 7.27 \\
\hline \multicolumn{5}{|l|}{ 2. Re-iteration } \\
\hline - Negative & -0.09 & 0.13 & 0.22 & 2.07 \\
\hline - Neutral & 0.03 & -0.03 & -0.06 & -0.99 \\
\hline - $\quad$ Positive & 0.06 & 0.17 & 0.11 & 1.93 \\
\hline 3. Downgrades & -0.59 & -0.84 & -0.25 & -6.25 \\
\hline 4. Upgrades & 0.55 & 0.94 & 0.39 & 10.64 \\
\hline
\end{tabular}




\section{Table 5: Market reaction and the EU regulation}

This table reports the coefficients and the t-stats of Model 1 for upgrades, positive initiations. The model is:

$$
\begin{aligned}
\text { CAR }_{b, j, t} & =a_{0}+a_{1} \text { PostLaw }_{j, t}+a_{2} \text { PubEnf }_{j, t}+a_{3} \text { Conflicts }_{a, j, t}+a_{4} \text { Rep }_{a, t}+a_{5} \text { PostLaw }_{j, t} \times \text { Conflicts }_{b, j, t}+a_{6} \text { PostLaw }_{j, t} \times \text { Rep }_{b, t} \text { CAR is the } \\
& +c_{1} \text { Dcons }_{b, j, t}+c_{2} \text { Follow }_{b, j, t}+c_{3} \text { BigBroker }_{b, t}+c_{4} \operatorname{Re}_{b, j, t}+c_{5} \operatorname{LnNbAn}_{j, t}+c_{7} \text { CER }_{j, t}+\varepsilon_{b, j, t}
\end{aligned}
$$

cumulative abnormal return defined in Section 4.1. It measures the market reaction of broker's $b$ recommendation on firm $j$ released at date $t$. PostLaw is a dummy variable that equals 1 after the transposition of CD2003/124 and CD2003/125 into national laws and 0 before. PubEnf measures the distance of public enforcement among regulations pre-MAD. Conflicts is a dummy variable that is measure in two different ways: a) $C M A D$ that equals 1 if broker " $b$ " underwrote capital issuance from firm $j$ during the last twelve months and 0 otherwise, and b) $C I B$ that equals 1 if broker " $b$ " was an investment bank over the past twelve months and 0 otherwise. In Panel A (B), we report the results for $C M A D(C I B)$. Rep is a dummy variable that equals 1 if broker " $b$ " is ranked in the Top 10 decile of European investment banks. Dcons is the spread of the current recommendation from the "consensus" defined as the average of the ratings of the recommendations issued over the last six months on firm $j$. Follow measures the numbers of recommendations issued by others analysts on the same firm during the ten-day period preceding the current recommendation. BigBroker is equal to 1 if the broker is in the first decile in terms of recommendations issued over the previous year. Rel is a dummy variable equal to 1 indicating whether an annual earnings forecast was issued revision the recommendation and 0 otherwise. $L n N b A n$ is the logarithm of the numbers of analysts having issued recommendations over the last six months on firm $j$. CER is a dummy variable that takes the value 1 if the recommendation is issued contemporaneous to an earnings announcement. These variables are defined in Section 4.2.1. Coefficients significant at the $1 \%(5 \%)$ level are in bold (italics) and heteroscedastic consistent White t-statistics are in parenthesis below. The adjusted$\mathrm{R}^{2}$, the Fisher statistics and the number of observations are indicated below. The last two rows report the value of reputation after MAD and the the t-stat under the null of no effect. 


\begin{tabular}{|c|c|c|c|c|c|c|}
\hline & \multicolumn{3}{|c|}{$C M A D$} & \multicolumn{3}{|c|}{$C I B$} \\
\hline & Upgrade & Positive init. & Downgrade & Upgrade & Positive init. & Downgrade \\
\hline \multirow[t]{2}{*}{ C } & 0.0018 & 0.0015 & -0.0039 & 0.0018 & 0.0019 & -0.0036 \\
\hline & 1.97 & 0.99 & -3.64 & 1.87 & 1.23 & -3.30 \\
\hline \multirow[t]{2}{*}{ PostLaw } & 0.0045 & 0.0044 & -0.0036 & 0.0037 & 0.0037 & -0.0030 \\
\hline & 11.10 & 5.89 & -8.44 & 7.12 & 3.83 & -5.36 \\
\hline \multirow[t]{2}{*}{ PubEnf } & 0.0026 & 0.0032 & -0.0009 & 0.0026 & 0.0035 & -0.0008 \\
\hline & 2.94 & 1.82 & -0.91 & 2.94 & 1.97 & -0.76 \\
\hline \multirow[t]{2}{*}{ Conflicts } & 0.0017 & -0.0015 & -0.0062 & 0.0002 & -0.0013 & -0.0010 \\
\hline & 0.92 & -0.64 & -2.44 & 0.47 & -1.59 & -1.89 \\
\hline \multirow[t]{2}{*}{ Rep } & 0.0029 & 0.0027 & -0.0030 & 0.0030 & 0.0029 & -0.0031 \\
\hline & 5.25 & 2.23 & -4.61 & 5.41 & 2.34 & -4.72 \\
\hline \multirow[t]{2}{*}{ PostLaw*Conflicts } & -0.0027 & -0.0005 & -0.0079 & 0.0016 & 0.0014 & -0.0016 \\
\hline & -0.99 & -0.13 & -1.69 & 2.03 & 0.95 & -1.95 \\
\hline \multirow[t]{2}{*}{ PostLaw*Rep } & -0.0006 & 0.0048 & 0.0038 & -0.0014 & 0.0041 & 0.0042 \\
\hline & -0.67 & 2.22 & 3.78 & -1.44 & 1.79 & 3.84 \\
\hline \multirow[t]{2}{*}{ Dcons } & 0.0014 & -0.0007 & 0.0013 & 0.0014 & -0.0006 & 0.0012 \\
\hline & 6.07 & -1.15 & 4.99 & 6.04 & -1.04 & 4.92 \\
\hline \multirow[t]{2}{*}{ Follow } & -0.0006 & -0.0005 & 0.0004 & -0.0006 & -0.0005 & 0.0004 \\
\hline & -4.85 & -1.51 & 2.87 & -4.80 & -1.62 & 2.83 \\
\hline \multirow[t]{2}{*}{ BigBroker } & 0.0033 & 0.0014 & -0.0038 & 0.0030 & 0.0019 & -0.0031 \\
\hline & 8.36 & 1.99 & -8.51 & 6.75 & 2.47 & -6.16 \\
\hline \multirow[t]{2}{*}{ Rel } & 0.0031 & 0.0031 & -0.0031 & 0.0031 & 0.0030 & -0.0031 \\
\hline & 4.10 & 2.74 & -3.31 & 4.13 & 2.70 & -3.33 \\
\hline \multirow[t]{2}{*}{$\operatorname{LnNbAn}$} & -0.0016 & -0.0020 & 0.0020 & -0.0016 & -0.0021 & 0.0020 \\
\hline & -5.67 & -4.16 & 6.25 & -5.57 & -4.20 & 6.02 \\
\hline \multirow[t]{2}{*}{ Cer3 } & 0.0139 & 0.0002 & -0.0078 & 0.0138 & 0.0001 & -0.0078 \\
\hline & 9.53 & 0.07 & -4.77 & 9.50 & 0.06 & -4.76 \\
\hline $\mathrm{R} 2$ & 0.0079 & 0.0043 & 0.0043 & 0.0079 & 0.0044 & 0.0040 \\
\hline $\mathrm{F}$ & 49.76 & 9.78 & 30.25 & 50.13 & 9.91 & 28.62 \\
\hline \multirow[t]{2}{*}{$\mathrm{N}$ obs } & 73711 & 24131 & 81780 & 73711 & 24131 & 81780 \\
\hline & \multicolumn{6}{|c|}{ Hypotheses } \\
\hline \multicolumn{7}{|l|}{ Reputation after MAD: } \\
\hline t-stat & 3.04 & 3.91 & 0.89 & 2.06 & 3.48 & 1.15 \\
\hline
\end{tabular}




\section{Table 6: Date of adoption of the EU regulation}

This table reports the t-stats of Davidson and Mc Kinnon method of model choice between non-nested models. The models are Model 1 with the adoption of the regulation measured as the transposition of MAD into national laws (one date per country), PostEC is with the adoption of the Commission Directives (December $23^{\text {rd }}, 2003$ ) and PostDL is the deadline for implementation into national laws (October $\left.12^{\text {th }}, 2004\right)$. Coefficients significant at the $1 \%(5 \%)$ level are in bold (italics)

\begin{tabular}{|c|c|c|c|c|c|c|}
\hline & \multicolumn{3}{|c|}{ CMAD } & \multicolumn{3}{|c|}{ CIB } \\
\hline & Upgrade & Positive init. & Downgrade & Upgrade & Positive init. & Downgrade \\
\hline \multicolumn{7}{|l|}{ Postlaw vs } \\
\hline PostEC & 8.00 & 5.12 & 7.21 & 7.69 & 5.06 & 7.31 \\
\hline PostEC vs & & & & & & \\
\hline Postlaw & 2.83 & 1.64 & -0.32 & 2.96 & 1.63 & 4.23 \\
\hline Postlaw vs & & & & & & \\
\hline PostDL & 5.16 & 2.42 & 6.47 & 5.40 & 2.54 & 6.62 \\
\hline PostDL vs & & & & & & \\
\hline Postlaw & 3.49 & 2.81 & -0.10 & 3.76 & 2.76 & -0.61 \\
\hline
\end{tabular}




\section{Table 7: Spill-over of US regulation into EU}

This table reports the coefficients and the t-stats of coefficients associated with the change in the US regulation for upgrades, positive initiations. The model is:

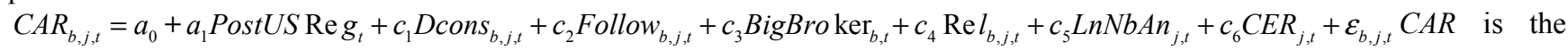
cumulative abnormal return defined in Section 4.1. It measures the market reaction of analyst $a$ 's recommendation on firm $j$ released at date $t$. PostUSReg is a dummy variable that measures the change in the US regulation. It is equal to 1 after SOX was passed into law and 0 before. Dcons is the spread of the current recommendation from the "consensus" defined as the average of the ratings of the recommendations issued over the last six months on firm $j$. Follow measures the numbers of recommendations issued by others analysts on the same firm during the ten-day period preceding the current recommendation. BigBroker is equal to 1 if the broker is in the first decile in terms of recommendations issued over the previous year. Rel is a dummy variable equal to 1 indicating whether an annual earnings forecast was issued revision the recommendation and 0 otherwise. $\mathrm{LnNbAn}$ is the logarithm of the numbers of analysts having issued recommendations over the last six months on firm j. $C E R$ is a dummy variable that takes the value 1 if the recommendation is issued contemporaneous to an earnings announcement. These variables are defined in Section 4.2.1. Coefficients significant at the 1\% (5\%) level are in bold (italics) and heteroscedastic consistent White t-statistics are in parenthesis below.

\begin{tabular}{lccc}
\hline & Upgrade & Positive init. & Downgrade \\
\hline \multicolumn{4}{l}{ Sample restricted to Global Banks } \\
Coef & 0.0007 & -0.0061 & -0.0010 \\
t-stat & 0.94 & -4.24 & -1.17 \\
R2 & 0.0052 & 0.0056 & 0.0031 \\
F & 16.14 & 7.33 & 10.78 \\
N obs & 20291 & 7853 & 22214 \\
Sample restricted to Local Banks & \\
Coef & 0.0006 & 0.0018 & 0.0031 \\
t-stat & 0.60 & 1.15 & 2.89 \\
R2 & 0.0008 & 0.0010 & 0.0011 \\
F & 2.23 & 1.70 & 2.97 \\
N obs & 11476 & 4776 & 12370 \\
\hline
\end{tabular}




\section{Appendix 1: Definition of Public Enforcement}

Headings 1, 2 and 3 are from La Porta et al. (2006, p. 7-8). Headings 4 and 5 are collected and adapted from the "Report on administrative measures and sanctions available in Member States under the Market Abuse Directive" available from the Committee of European Securities Regulators at: http://www.cesreu.org/index.php?page $=$ document_details\&id $=4975 \&$ from_id $=22$. Every sub-index is the average

\begin{tabular}{|c|c|}
\hline & 1. Characteristics of the Supervisor of securities markets \\
\hline Appointment & $\begin{array}{l}\text { Equals one if a majority of the members of the Supervisor are not } \\
\text { unilaterally appointed by the Executive branch of government; and } \\
\text { equals zero otherwise. }\end{array}$ \\
\hline Tenure & $\begin{array}{l}\text { Equals one if members of the Supervisor cannot be dismissed at the } \\
\text { will of the appointing authority; and equals zero otherwise. }\end{array}$ \\
\hline Focus & $\begin{array}{l}\text { Equals one if separate government agencies or official authorities are } \\
\text { in charge of supervising commercial banks and stock exchanges; and } \\
\text { equals zero otherwise. }\end{array}$ \\
\hline \multirow{2}{*}{$\begin{array}{l}\text { Supervisor } \\
\text { characteristics index }\end{array}$} & Equals the arithmetic mean of Appointment, Tenure and Focus. \\
\hline & 2. Power of the Supervisor to issue rules \\
\hline \multirow[t]{2}{*}{ Rule-making power } & $\begin{array}{l}\text { Equals one if Supervisor can generally issue regulations on stock } \\
\text { exchanges without prior approval of other governmental authorities; } \\
\text { equals one half if Supervisor can generally issue regulations on stock } \\
\text { exchanges only with the prior approval; equals zero otherwise. }\end{array}$ \\
\hline & 3. Investigative powers of the Supervisor art. 14.3. \\
\hline Documents & $\begin{array}{l}\text { Equals one if the Supervisor can generally issue an administrative } \\
\text { order commanding all persons to turn over documents; equals one } \\
\text { half if the Supervisor can generally issue an administrative order } \\
\text { commanding publicly traded corporations and/or their directors; } \\
\text { equals zero otherwise. }\end{array}$ \\
\hline Witness & $\begin{array}{l}\text { Equals one if the Supervisor can generally subpoena all persons to } \\
\text { give testimony; equals one half if the Supervisor can generally } \\
\text { subpoena directors of publicly traded corporations; equals zero } \\
\text { otherwise. }\end{array}$ \\
\hline \multirow{3}{*}{$\begin{array}{l}\text { Investigative powers } \\
\text { index }\end{array}$} & Equals the arithmetic mean of Documents and Witness. \\
\hline & 4. Administrative pecuniary sanctions: articles 6.3 and 6.5 \\
\hline & $\begin{array}{l}\text { Equals one if the maximum administrative pecuniary sanction is } \\
\text { higher than } 1000000 \text { EUR; equals one half if the maximum } \\
\text { administrative pecuniary sanction is higher than } 50000 \text { EUR (and }\end{array}$ \\
\hline
\end{tabular}




\begin{tabular}{|c|c|}
\hline & $\begin{array}{l}\text { lower than } 1000000 \text { EUR); equals } 0 \text { if the maximum administrative } \\
\text { pecuniary sanction is lower than } 50000 \text { EUR. }\end{array}$ \\
\hline & 5. Criminal sanctions articles: 6.3 and 6.5 \\
\hline Imprisonment & Equals one if the sanction can be imprisonment; equals 0 otherwise \\
\hline Fines & $\begin{array}{l}\text { Equals one if the maximum administrative pecuniary sanction is } \\
\text { higher than } 1000000 \text { EUR; equals one half if the maximum } \\
\text { administrative pecuniary sanction is higher than } 50000 \text { EUR (and } \\
\text { lower than } 1000000 \text { EUR); equals } 0 \text { if the maximum administrative } \\
\text { pecuniary sanction is lower than } 50000 \text { EUR. }\end{array}$ \\
\hline $\begin{array}{l}\text { Criminal sanctions } \\
\text { index }\end{array}$ & Equals the arithmetic mean of Imprisonment and Fines. \\
\hline $\begin{array}{l}\text { Public Enforcement } \\
\text { index }\end{array}$ & $\begin{array}{l}\text { Equal the arithmetic mean of the "Supervisor characteristics index, } \\
\text { the Power of the Supervisor to issue rules, the Administrative } \\
\text { pecuniary sanctions, the Investigative powers index and the Criminal } \\
\text { sanctions index }\end{array}$ \\
\hline
\end{tabular}


Appendix 2: Definition of control variables

\begin{tabular}{|l|l|l|c|}
\hline Variable & Name & Definition & Sign \\
\hline $\begin{array}{l}\text { Magnitude of the } \\
\text { innovation }\end{array}$ & Dcons & $\begin{array}{l}\text { Deons } b_{b, j, t}=\operatorname{Re} c_{b, j, t}-\operatorname{Re} c_{i, j, t} \\
\operatorname{Re} c_{a, j, t} \text { is the recommendation issued by broker } a \text { on firm } j \text { at time } t \text { and } \operatorname{Re} c_{, j, t} \text { is } \\
\text { the consensus (mean of the last recommendations issued for firm } j \text { less than a year } \\
\text { ago) }\end{array}$ & + \\
\hline Timeliness & Follow & $\begin{array}{l}1 \text { if the current recommendation is issued less than } 10 \text { days after the previous } \\
\text { recommendation and is consistent with it (both the previous and the current } \\
\text { recommendation are either favourable or unfavourable), } 0 \text { otherwise. }\end{array}$ & + \\
\hline Big Broker & BigBroker & $\begin{array}{l}1 \text { if the broker belongs to the first decile in terms of recommendations issued over } \\
\text { the previous year, } 0 \text { otherwise. }\end{array}$ & + \\
\hline Reliability & Rel & $\begin{array}{l}1 \text { if an earnings forecast was issued by the same analyst during the ten-day period } \\
\text { surrounding the recommendation, } 0 \text { otherwise. }\end{array}$ & + \\
\hline Coverage & LnNbAn & $\begin{array}{l}\text { LnNbAn } n_{j, t}=L n\left(N b A n_{j, t}\right) \text { where } N b A n_{j, t} \text { is the number of analysts following the } \\
\text { firm }\end{array}$ & + \\
\hline Broker Size & BigBroker & $\begin{array}{l}1 \text { if broker belongs to the first decile in terms of recommendations issued over the } \\
\text { previous year, } 0 \text { otherwise. }\end{array}$ & + \\
\hline Earnings release & CER & 1 if earnings are released during the event window, 0 otherwise. & + \\
\hline
\end{tabular}

The signs in column 4 represent the expected sign of the corresponding variable on stock returns for upgrades; downgrades have the opposite sign except Dcons. When Dcons is negative (positive), the corresponding coefficient has to be positive in order to amplify the negative (positive) reaction. 